\title{
Organizational Culture and It's Relation to Administrative Innovation in Private Schools in Jordan from the Point of View of Teachers
}

\author{
Awad Abdellatif Al Tarawneh \\ Curricula and methods of \\ teaching - Educational Sciences \\ The University of Jordan School \\ awadat1976@yahoo.com
}

Received 3/9/2019

\author{
Issa Abdulwahab Al Tarawneh \\ Measurement and Statistics - \\ Educational Sciences \\ Independent Election Commission \\ spss_esa@yahoo.com
}

\author{
Jawaher Abdulkarim Al Ghoweri \\ Curricula and methods of teaching - \\ Educational Sciences \\ The University of Jordan School \\ jawaher_marar@yahoo.com
}

Accepted 17/10/2019

\begin{abstract}
:
The study aims to recognize the relationship between organizational culture and administrative innovation in private schools in Jordan. The study uses the descriptive method through the distribution of two questionnaires: the first is to measure the organizational culture, and the second is to measure administrative innovation.

The study sample consists of (197) teacher from private schools during the academic year 2018/2019, Validity and reliability coefficients were ensured for the tool. The results of the study shows that the organizational culture level among the principals of private schools is high, and the level of administrative innovation is moderate.

The results of the study show a statistically significant positive correlation relationship between the organizational culture and administrative innovation. The study shows no statistically significant differences in teachers' estimates of the level of organizational culture among school principals due to gender and experience variables.
\end{abstract}

Keywords: organizational culture, administrative innovation, private schools, Jordan. 


\section{الثقافة التظيمية وعلاقتها بالإبداع الإداري في المدارس الخاصة في الأردن من وجهة نظر المعلمين}

\author{
جواهر عبدالكريم الغويري \\ مناهج وطرق تدريس - العلوم التربوية الغرية

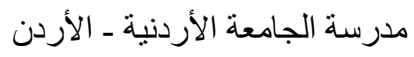 \\ jawaher_marar@yahoo.com
}

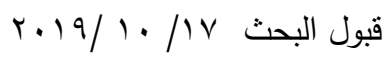

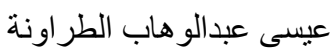 \\ قياس و إحصاء ـ العلوم التربوية الطية

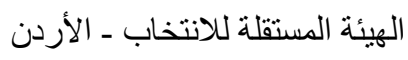 \\ spss_esa@yahoo.com
}

\author{
عوض عبداللطيف الطر اونة \\ مناهج وطرق تدريس - العلوم التربوية

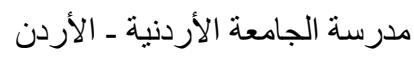 \\ awadat1976@yahoo.com
}

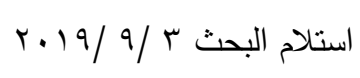

هدفت الدراسة إلى التعرف على العلاقة بين الثقافة التنظيمية والإبداع الإداري في الددارس الخاصة في الأردن من وجهة نظر المعلمين،

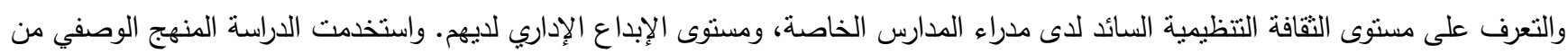

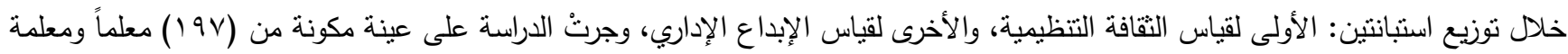

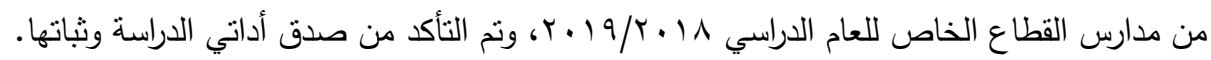

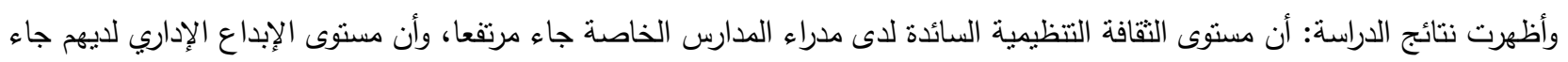

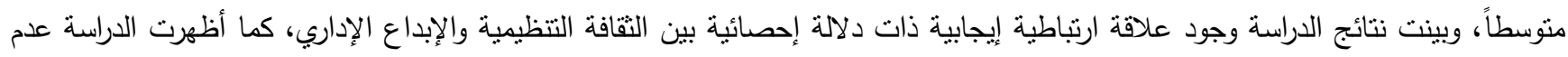

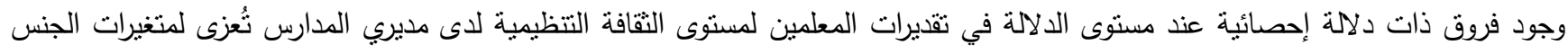

كما أن الثقافة التتظيمية تعدّ عنصراً أساسياً في النظام العام

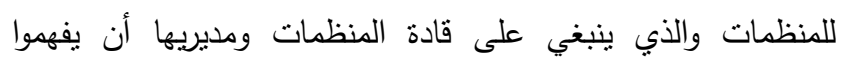

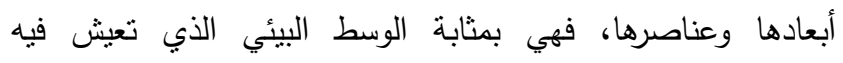

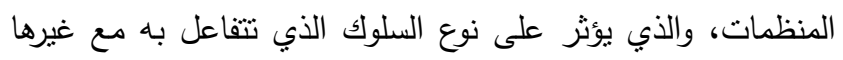
من المنظمات أو مع العاملين فيها. وتجدر الإثارة إلى أن النقافة التتظيمية نحظى باهنمام كبير

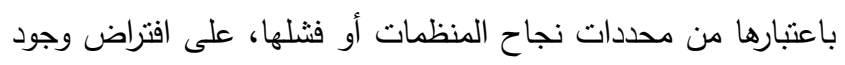

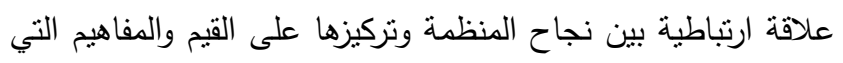

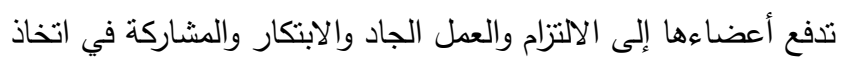

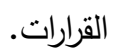

فالتقافة التنظيمية هي نتاج ما اكتسبه العاملون من أنماط

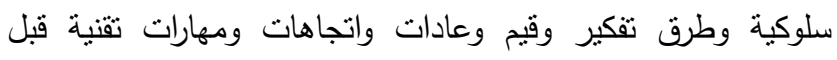

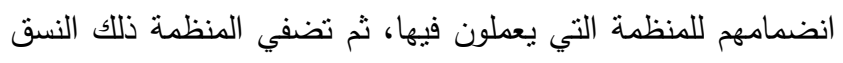

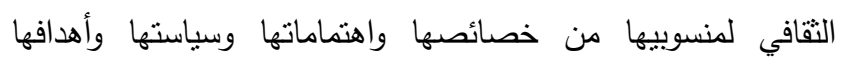

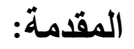

تُعدّ" الثقافة دستوراً يُنظم الحياة الاجتماعية ويُحدد علاقات

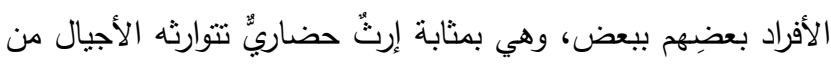

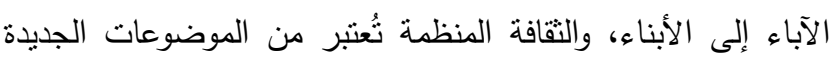

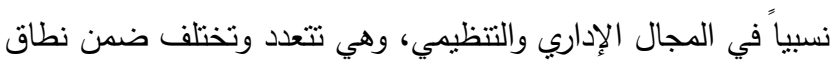

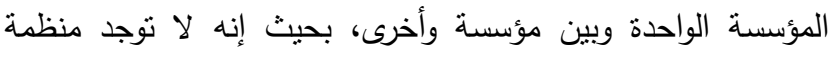

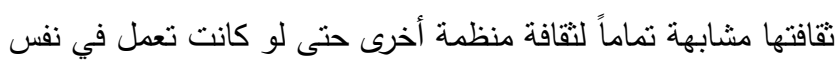
القطاع. إن الثقافة التنظيمية تشكل تحدياً لأي تنظيم نظراً لما لها من

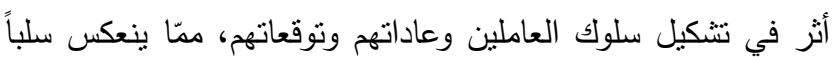

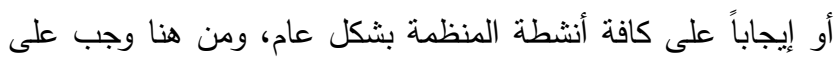

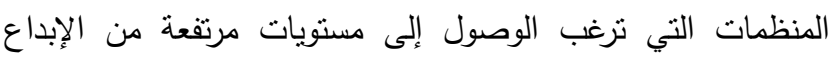

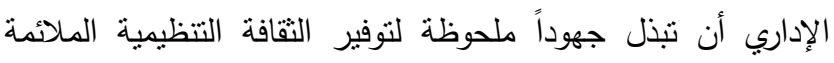

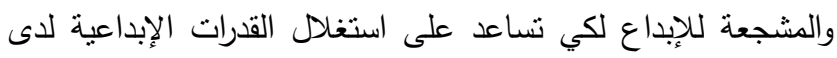

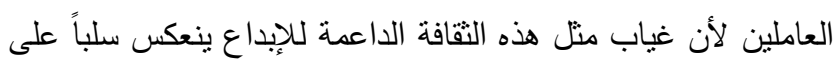
التفكير الإبداعي لاى هؤلاء العاملين. 
التقافة التنظيمية وعلاقتها بالإبداع الإداري في المدارس الخاصة في الأردن من وجهة نظر المعلمين.

في حين ترى(9') أن ثقافة التعاطف الإنساني تعتمد على التعاطف والاحترام والعلاقات الطيبة بين العاملين، لكن التركيز على تُّى الجانب الإنساني، قد يعيق تتفيذ العمل وقد يؤدي إلى تجاهله، وأخيرا

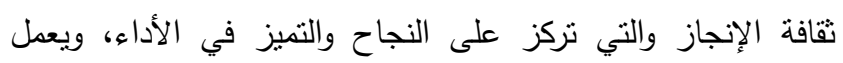

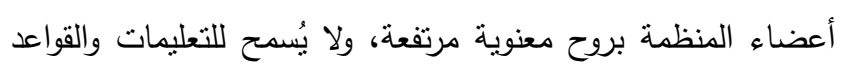
الوقوف بوجه العمل.

وتأني أهمية الثقافة التنظيمية في المدارس بارتباطها بالفاعلية التتظيمية، فهي تؤثر في تحصيل الطلبة، وتعدل على تحفيز العاملين والطلبة والمعلمين لتحقيق الإبداع الذاتي، وتزداد أهمية الثقافة التتظيمية بالنسبة لمديري المدارس الذين يتواجدون في قمة الهرم

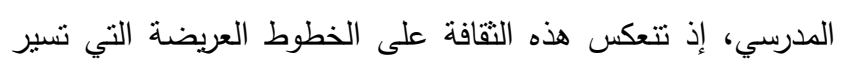

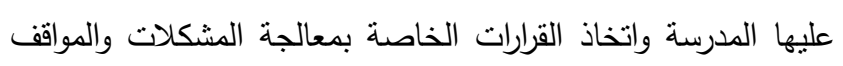

المختلفة(rr) ( (r)

وتعتبر الإدارة الإبداعية سمة من سمات المنظمات الحديثة، فلم

تعد البيئة الخارجية للمنظمات مستقرة كما كانت، بل الحركية والديناميكية دن سماتها، فالعصر الحالي يتميز بالتغيرات المتسارعة

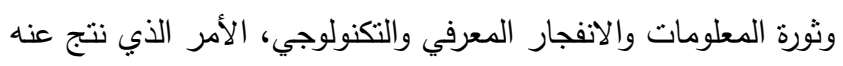

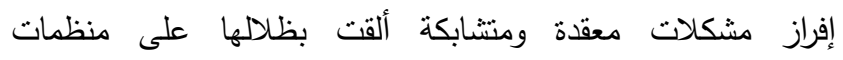
العمل(ror)، وبالتالي تحنّم على هذه المنظمات ابتكار حلول لمواجهة تللك المشكلات، حيث يتطلب حل هذه المشكلات استخدام طرق جديدة إبداعية ونبذ الطرق والإجراءات القديمة، ولا يتم ذلك إلا بإيجاد الأشخاص المبدعين وتوفير الوسائل المناسبة التي تساعد على إيجاد طرق جديدة وحلول إدارية سريعة. ومن هنا اعتبر الإبداع الإداري أحد المكونات الإدارية الأساسية للمنظمات الإدارية بشكل عام والمنظمات

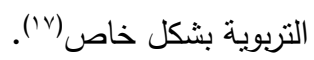

ويعرف جونيس(rV) الإبداع الإداري بأنه تبني التتوع وإدارة

الموارد البشرية والمادية بشكل فاعل، والقدرة على حل النزاعات التتظيمية والقدرة على التكيف مع متغيرات العمل. أما رتشارد وموجيرز(r9) المشار إلبهها في دراسة(؟) فقد عرفا الإبداع الإداري أنه "مفهوم بنطوي بشكل رئيس على قدرات المدير في تنبي ممارسات إدارية مبدعة مثل القدرة على استغلال الموارد البشرية والمادية المتوفرة بشكل إبداعي، وبالتالي فإن الإبداع الإداري يعتمد على العنصر البشري بشكل أساسي من خلال طرح حلول مميزة للمشكلات، وأداء العمل بأساليب وطرق جديدة في ظل استخدام العناصر الآتية: الأصالة، الطلاقة، المرونة، المخاطرة، القدرة على التحليل، الحساسية للمشكلات، الخروج عن المألوف سواء للفرد نفسه أو للمنظمة التي

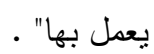
ويرى(ז)" بأن الإبداع يقود إلى التجديد والتطوير، ومدير

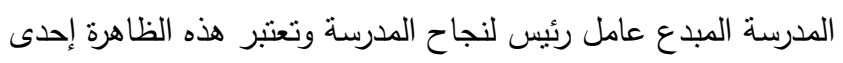
الظواهر التي تهتم بها المجتمعات المتقدمة، حيث تستطيع المدرسة أن
وقيمها ما بحدد شخصية المنظمة ويميزها عن غيرها من

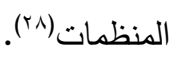
وتلعب التقافة التتظيمية دوراً مُهمّا في التغيير والتطوير الذي يُعدّ أهم سمة من سمات العصر الحديث، حيث نتضح أهميتها في المؤسسات التربوية بشكل عام والمدارس بشكل خاص لما لها من انعكاس على الفعالية التنظيمية والمناخ التظظيمي، من حيث تحصيل الطلبة، وتحقيق الانتماء والإنجاز والولاء، والعمل بروح الفريق، وتحقيق ذات العاملين(ء)

لذا فالإدارة التربوية تُبدي اهتماماً بالغاً لبيئة العمل في التين المؤسسات التربوبة لاقتتاعها الراسخ بأن الإنسان هو الثروة الحقيقية

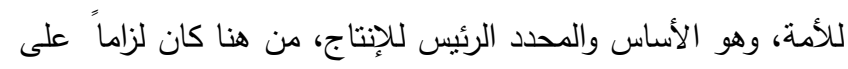
المؤسسات التربوية الاهتمام بالثقافة التتظيمية لما لها من دور كبير في توجيه سلوك الأفراد في المنظمات التي يعملون فيها بما تتضمنه من قيم وأخلاقيات واتجاهات وعادات، فهي تلعب دوراً مهماً في تشكيل عادات الفرد وقيمه واتجاهاته وطرق تعامله مع الأفراد والأشياء من حوله(·). وتُعرّف الثقافة التظيمية على أنها مجموعة القيم والمعتقدات التي تشكل منهج تفكير أعضاء المنظمة وإدراكاتهم، وتؤثز في أسلوب

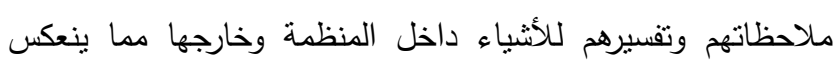
على سلوك الأفراد وممارسات الإدارة وأسلوبها المتبع لأجل تحقيق رسالة المنظمة (')

وللتقافة التتظيمية مجموعة من المُكونات والعناصر التي تكوّن مجتمعةً مفهوم التقافة التظيمية، فالمكون الأول هو القيم التظيمية والتي يُقصد بها وجود تفاهم بين أفراد بيئة عمل ما أو منظمة ما على مائي سلوكات وتوجهات متعارف عليها، والمكون الثاني هو المعتقدات التتظيمية، ويُقصد بها الأفكار المشتركة لدى العاملين في بيئة عملهم

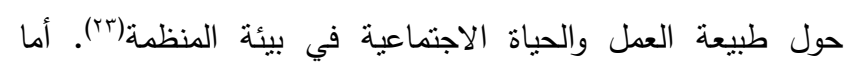
المكون الثالث فهو الأعراف التتظيمية وهي ما تعارف عليه أفراد المنظمة دون الحاجة إلى كتابته كالقواعد والقوانين، وتسود هذه وهيه الأعراف بين الأفراد ويلتزمون بها، والمكون الأخير هو التوقعات

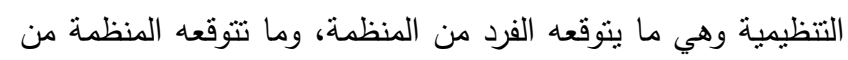

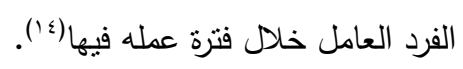
وقد صنَف "كوتر وهسكت" التقافة التتظيمية إلى أربعة أنواع : ثقافة القوة، ويتميز القائد في هذا النوع بالحزم، وقوة شخصيته وحضوره المميز، ويهنم بتابعيه المخلصين ويحميهم ويكافئهم، ويتوقع الكثير

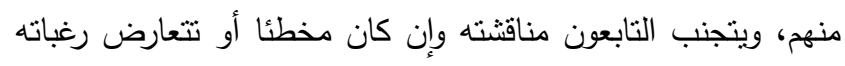
مع منطلبات العمل، أما ثقافة النظم و والأدوار فترتكز على النظام

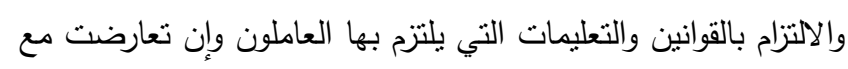
منطلبات العمل، والخروج عنها جريمة وهذا من شأنه قتل روح المبادرة

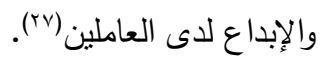


ويتكون الإبداع من عدد من المكونات أو العناصر : المكون الأول: الطلاقة (Fluency): وهي تمثل الجانب الكمي في الإبداع،

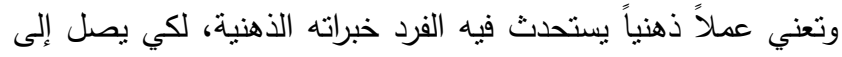

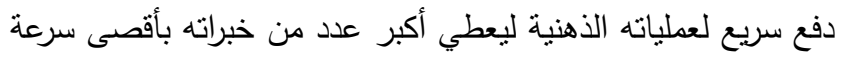
وأعمق أداء، وهي في جوهرها عملية تذكر واستدعاء اختبارية لمعلومات أو خبرات أو مفاهيم سبق نعلمها لتتكامل مع الخبرات

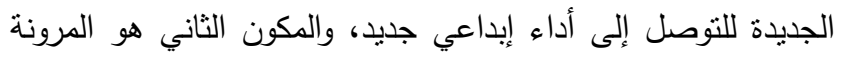
(Flexibility)

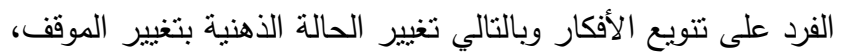

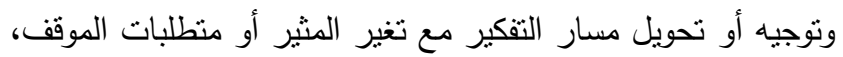

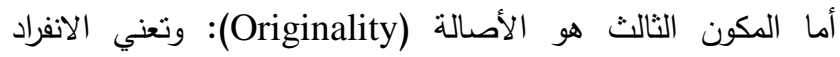

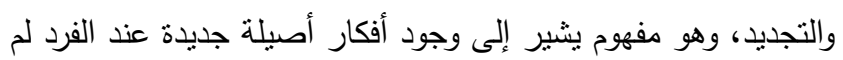

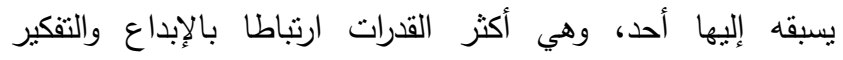
الإبداعي، وتعني قدرة الفرد على إعطاء استجابات أصيلة وجديدة

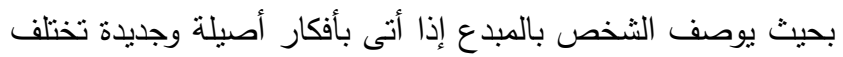

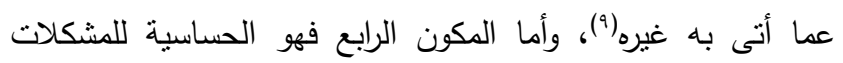
حاجدsitivity to problems) حاجات أو عناصر ضعف في البيئة أو الموقف، كما هي مؤشر على الى لئ

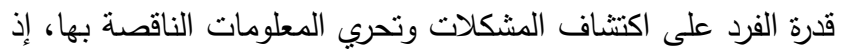

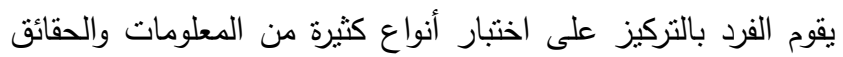

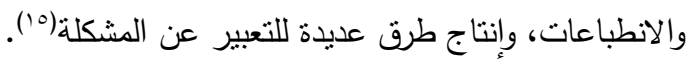

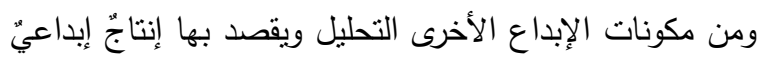

وابتكار يتضمن عملية انتخاب أو اختبار أو تفتيت أي عمل جديد إلى الى التي

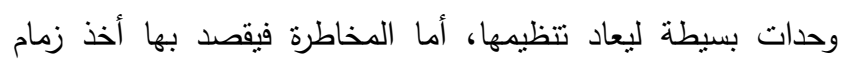

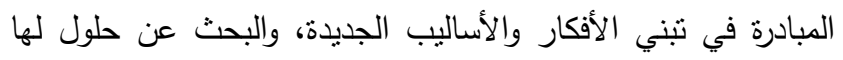

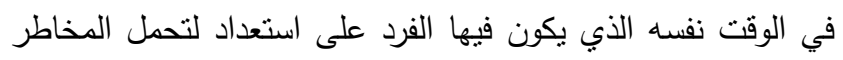
الناتجة عن الأعمال التي يقوم بها ولديه الاستعداد لتحمل المسؤوليات

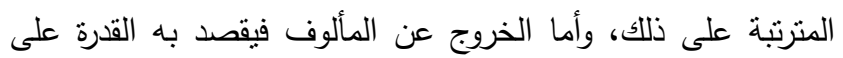
التحرر من النزعة التقليدية والتطورات الثائعة، والقدرة على التعامل مع الأنظمة الجامدة وتطويع واقع العمل، ويتطلب ذلك شجاعة التهات

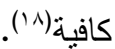

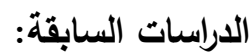

ويمكن تقسيمها إلى ثلاثة محاور : الدراسات التي تتاولت الثقافة

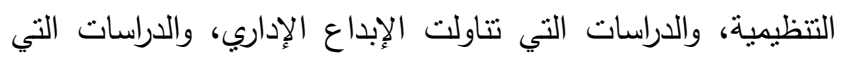
تتاولت النقافة التنظيمية والإبداع الإداري معاً.

أولاً: الدراسات التي تناولت الثقافة التنظيمية:

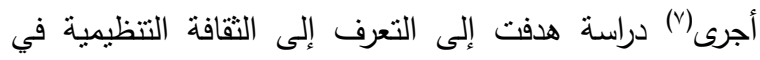

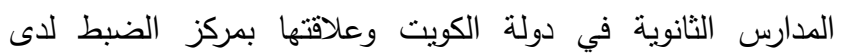

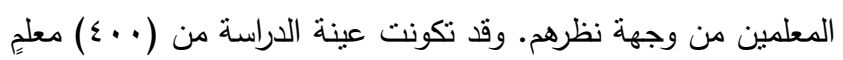

تواكب ركب الحضارة، وأن يكون لها موقع على الخريطة التزبوية

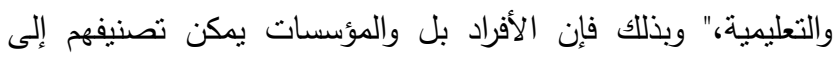

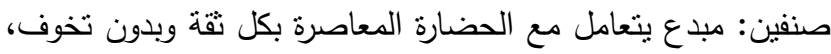
متجدد في فكره، وآخر مقلد ينتظر من الآخرين أن يمنوا عليه بفكرهم

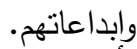
فالإبداع والابتكار من الضرورات والعناصر المهمة، والسمات

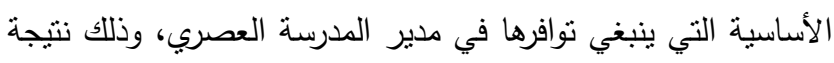
لتزايد الطموحات، وتعدد الحاجات، وتتوعها، حيث تشكّل ظاهرة

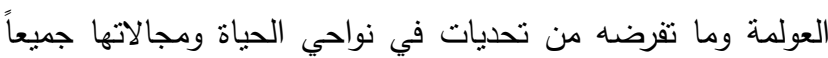
نقطة جوهرية في ضرورة الأخذ بالإبداع والابتكار في إدارة العملية

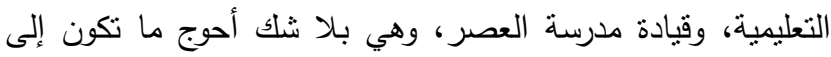

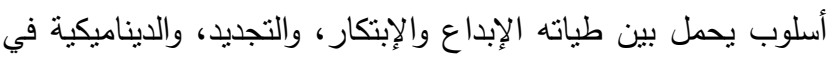
كافة مناحي العمل الإداري ككل(ب). فالمدير المبدع هو المدير القادر على كسر الروتين، وترك الإئ الممارسات الروتينية التقليدية المعتادة، ومحاولة إدخال بعض الأفكار

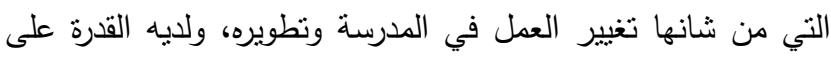

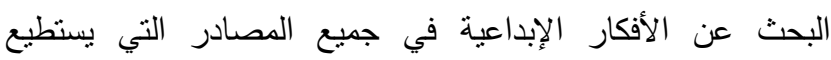

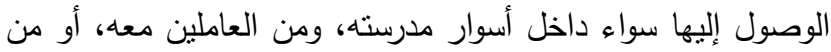

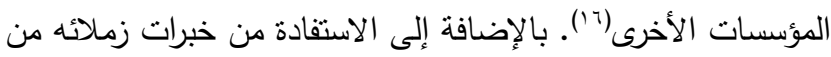

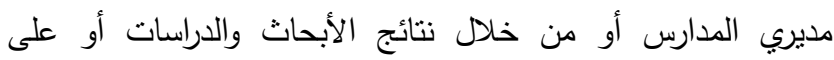
صفحات الإنترنت، ولديه القدرة على تنفيذ الأفكار الإبداعية

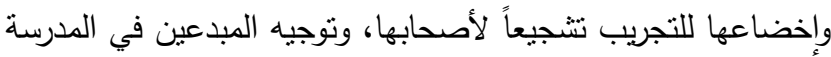
طلاباً كانوا أم معلمين ويساعدهم في تحسين قدراتهم الإبداعية وتوجيهها إلى المجالات الأكثر أهمية في المدرسة، وجعل الإبداع جزءاً من نقافة المدرسة (^). وقد تعددت وتتوعت تعريفات الإبداع، فقد عرفه(r) بأنه مزيج من الخيال العلمي المرن لتطوير فكرة قديمة أو إيجاد فكرة جديدة ينتج

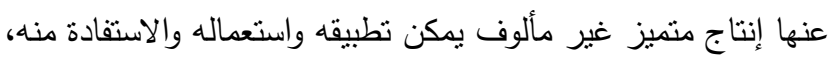
في حين براه جيلفورد(r) بأنه مجموعة من السمات الاستعدادية التي لتئي تتضمن الطلاقة في التفكير والمرونة والأصالة والحساسية للمشكلات

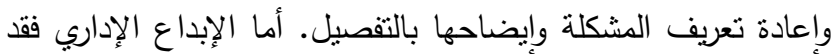

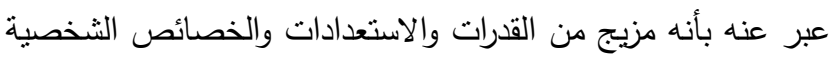
التي إذا ما وجدت بيئة إدارية مناسبة يمكن أن ترقى بالعمليات العقلية لتؤدي إلى نتاجات أصيلة ومفيدة سواء بالنسبة لخبرات الفرد السابقة

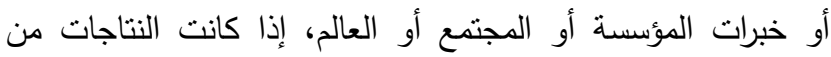

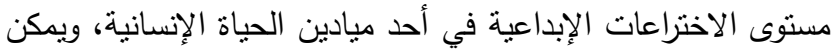

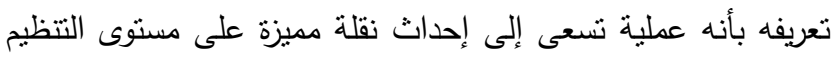

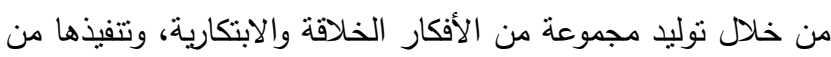

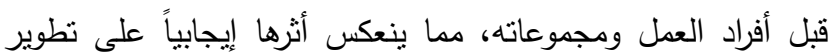
المؤسسة أو المنظمة(7). 
بشكل مباشر على جودة عمليات التعلم في المنظمة، ويكمن دور

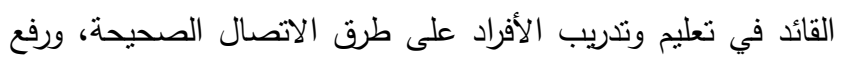
مستوى المشاركة في عمليات صنع القرارات، وأن للتقافة التنظيمية

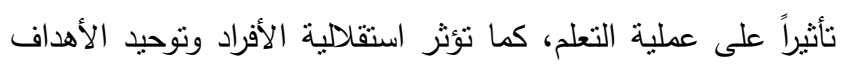

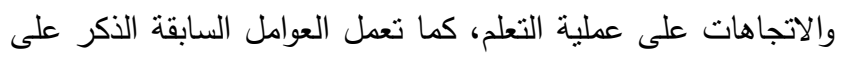

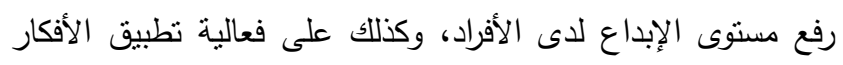

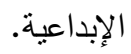

وهدفت دراسة(·r) إلى تعرف مستوى الإبداع الإداري لدى مديري

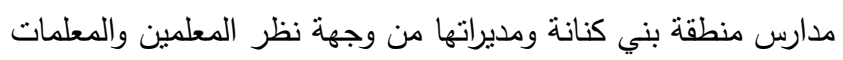

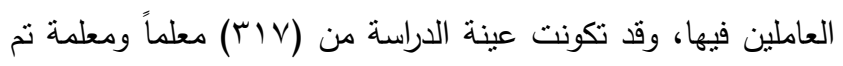

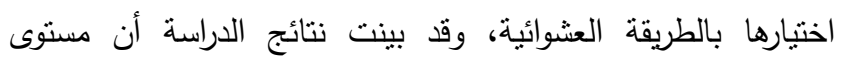

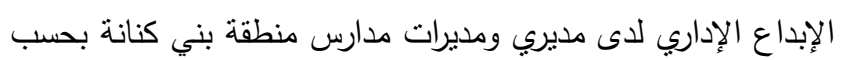

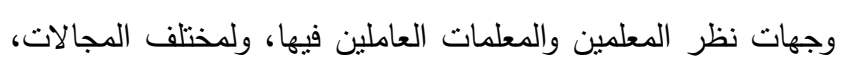

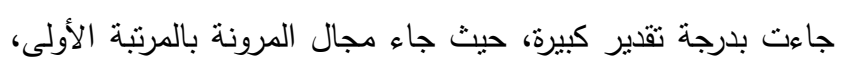

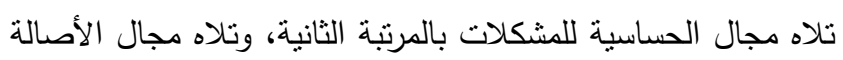
بالمرتبة الثالثة، وتلاه مجال الطلاقة بالمرتبة الرابعة والأخيرة. ثالثاً: الدراسات التي تناولت الثقافة التنظيمية والإبداع الإداري

أجرى() دراسة هدفت إلى التعرف على أثر الثقافة التنظيمية على الإبداع الإداري في المؤسسات العامة في المملكة العربية

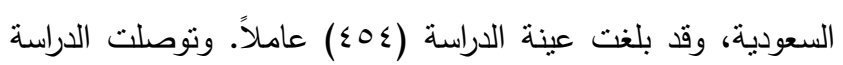
إلى النتائج التالية: تتوفر جميع القيم المكونة للتقافة التتظيمية في

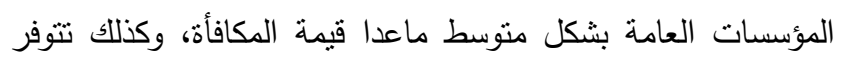

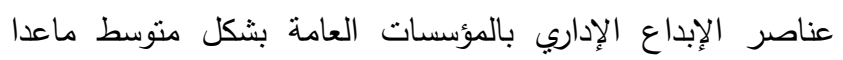
عنصر الخروج عن المألوف، وتثير الدراسة إلى وجود ارتباط إيجابي

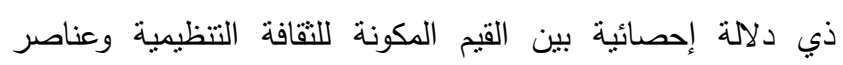
الإبداع الإداري، وأن أهم القيم المكونة للثقافة النتظيمية التي تؤثثر على الإبداع الإداري بشكل عام هي (الكفاءة و فرق العمل).

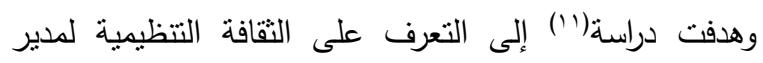

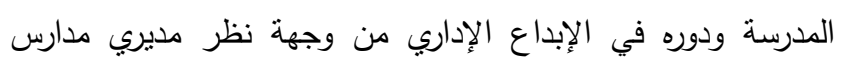

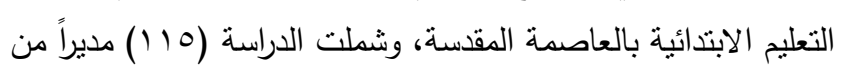

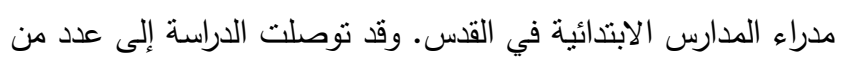

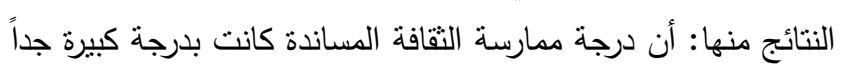

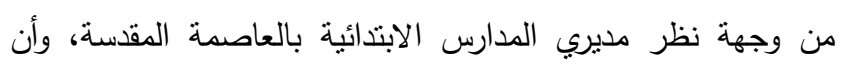
درجة ممارسة عنصر الأصالة كعنصر من عناصر الإبداع الإداري

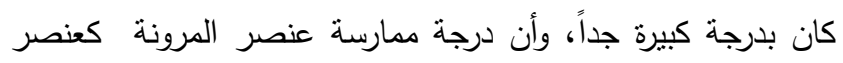

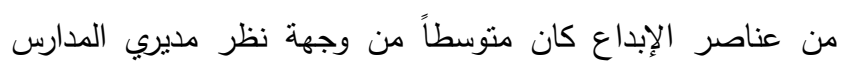
الابتدائية بالعاصمة المقدسة. وقام(r) بدراسة هدفت الى التعرف على العلاقة بين الثقافة

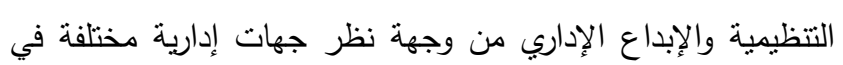

ومعلمة. وقد نوصلت نتائج الدراسة إلى أنّ مستوى الثقافة التنظيمية

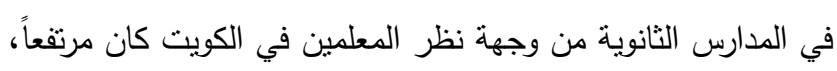

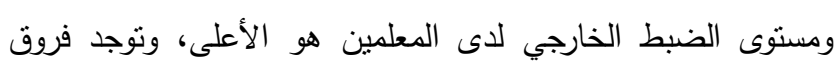
ذات دلالة إحصائية لدرجة الثقافة التنظيمية في المدارس الثانوية في لألئي

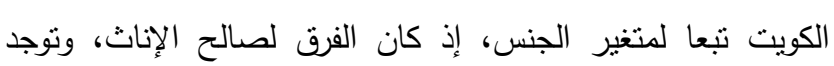

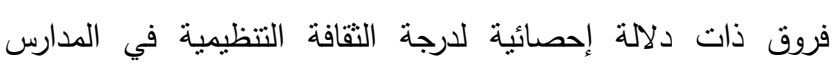

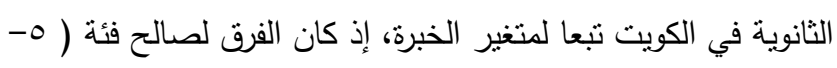

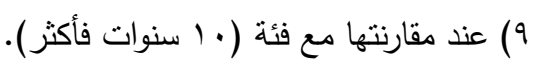

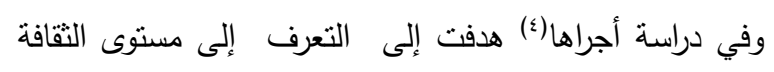

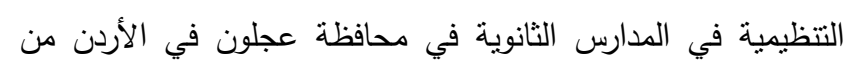

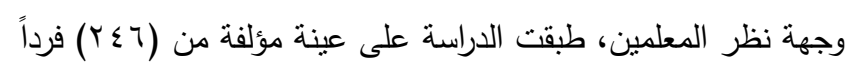
وأظهرت نتائج الدراسة: أن نقدير الدرجة الكلية لمسنوى الثقافة

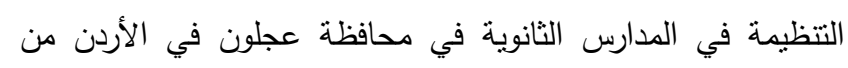

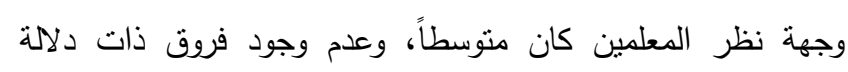

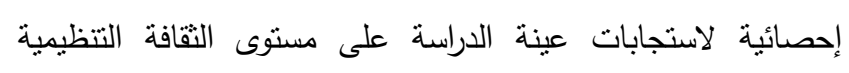

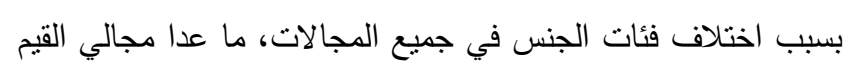

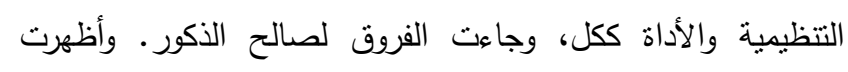

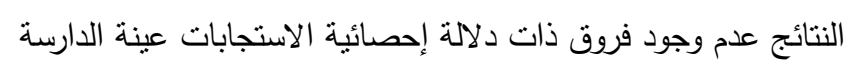

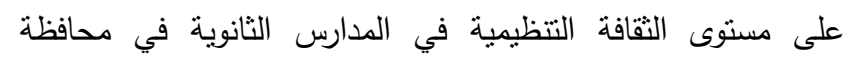
عجلون في الأردن من وجهة نظر المعلمين تُعزى لمتغيري المؤهل العلمي وسنوات الخبرة. ثانياً: الاراسات التي تناولت الإبداع الإداري:

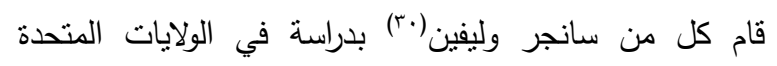

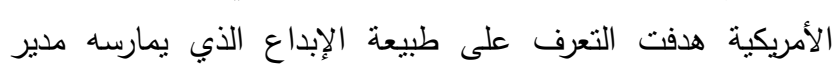

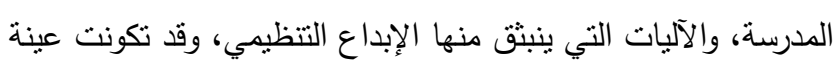

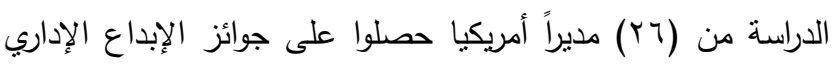
على مدى (·r) عاماً، تم الحكم عليها من خلال استثارة الخبراء

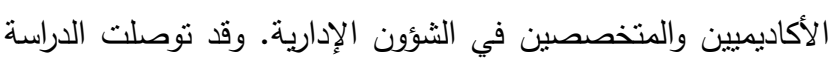
إلى النتائج التالية: أن الإبداع ينشأ عن النطور في المعرفة النئنة والخبرة

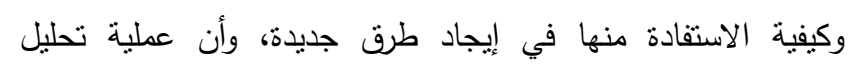

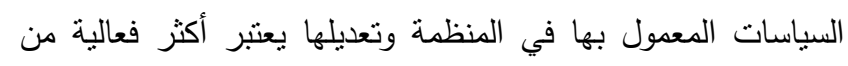
تبني سياسات جاهزة من خارج المنظمة. وأجرى وافري(") دراسة ميدانية في الولايات المتحدة الأمريكية

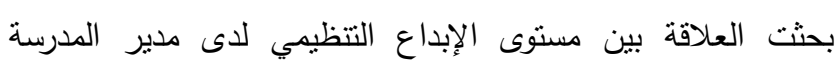
الأمريكية والتعلم الفعال، وتهدف الدراسة أيضا إلى وصف الإعلى المؤشرات

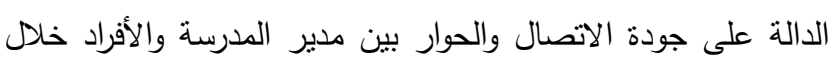

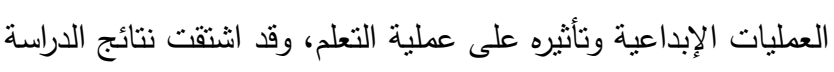
من سلسلة من الدراسات الميدانية التي أقيمت على (r) (I) مشروعاً مدرسياً في (T) مدرسة أمريكية. وقد نوصلت الدراسة إلى النتائج الآتية: أن جودة ونمط المحادثة خلال تطبيق الأساليب الإبداعية يؤثر 
كما استفاد الباحثون في دراستهما من الدراسات السابقة في مقدمة الدراسة وإطارها النظري، وأداة الدراسة (الاستبانة)، والأساليب الإحصائية المستخدمة، وفي تفسير نتائج الدراسة ومنافشتها.

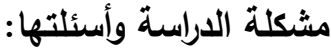

تواجه المنظماتُ التزبوية بشكل عام والمدارس بشكلٍ خاص العديدَ من القضايا والمشكلات التي تتطلب من قياداتها الابتعاد عن النهج التقليدي في حلّ المشكلات، ومحاولة نوظيف النهج الإبداعي في حلّها، ولا زالت الإدارة التعليمية والمدرسية في العالم العربي تعاني من أزمة إدارية واضحة في ظل النظام التعليمي الراهن. ولعل أبرز

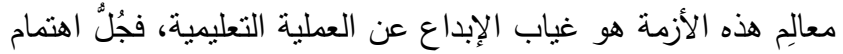
الإدارات التعليمية قائمٌ على الحلول التقليدية والأفكار النمطية وخصوصا في مجال القطاع التعليمي الخاص، فددراء المدارس فيه يتبعون لمجلس إدارة غالبا ما نكون هي المسيطرة ومدراء المدارس هم الفيعي

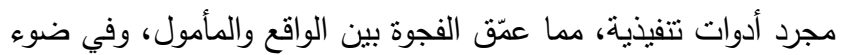

ذللك يمكن صياغة أسئلة الدراسة الآتية: • السؤال الأول: ما مستوى الثقافة التظيمية السائدة لدى

مدراء الدارس الخاصة من وجهة نظر المعلمين؟

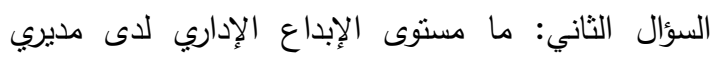
الدارس الخاصة من وجهة نظر المعلمين؟ السؤال الثالث: هل توجد علاقة ذات دلالة إحصائية عند

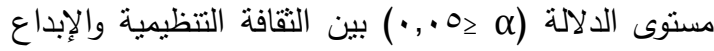

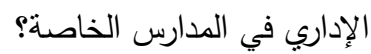
السؤال الرابع: هل هناك فروق ذات دلالة إحصائية عند الحارئ مستوى الدلالة (ه> • , , ) في مستوى الثقافة التتظيمية في المدارس الخاصة تُخزى إلى متغيرات (الجنس، الخبرة)؟

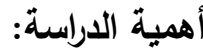

يتوقع أن نُقدّم هذه الدراسة معلوماتٍ على قدر من الأهمية

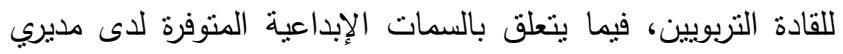
المدارس الخاصة وعلاقتها بالثقافة التنظيمية، كما يُؤمل أن تُشهم هذه الدراسة في تحسين الواقع العملي للمنظمات التربوية بشكل عام وللمدارس بشكل خاص، وذللك من خلال نوفير بيئة محفزة للإبداع الإداري، وتخطيط وتصميم البرامج الملائمة لجعل هذا الواقع أفضل. ومن جهة أخرى تتبع أهية هذه الدراسة من أهمية الثقافة النتظيمية التي تشكل الإطار الفكري والمرجعي للمؤسسات التزبوية، فهي بمنزله دليل للإدارة والعاملين في المؤسسة، وتُشكل لهم إطارا فكريا يوجه العلاقات والسلوكات التي يجب الاسترشاد بها في مدرسة
وزارة التربية والتعليم في الأردن، ونكونت عبنة الدراسة من جميع العاملين في وزارة التربية والتعليم كإدارة عليا بلغت (·•) إداريا، وجميع العاملين في المناطق التعليمية كالإدارة الوسطى بلغت (TAv) عاملاً. وقد توصلت الدراسة إلى النتائج الآتية: أن درجة الثقافة الثانية التنظيمية السائدة لدى العاملين متوسطة، وكذللك درجة الإبداع التزبوي السائد في المنظمة التزبوية الأردنية كانت متوسطة، كما توجد فروق ذات دلالة إحصائية لمتغير الجنس في إدراك الثقافة النتظيمية، في حين لا نوجد فروق ذات دلالة إحصائية للتغير الجنس في امتلاك المقدرات الإبداعية لاى العاملين في المنظمة التزبوية الأردنية. وتوجد فروق ذات دلالة إحصائية لكتغيرات "المؤهل التربوي، والدورات التدريبية في مجال الإدارة المدرسية، والدورات التدريبية في مجال

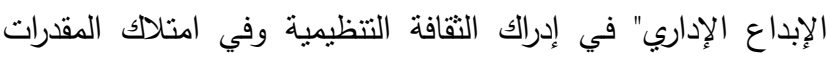
الإبداعية لاى العاملين في المنظمة التربوية الأردنية لصالح المؤهل والمتدرب. وتتشير النتائج إلى أن المستوى الأدنى من متغيرات

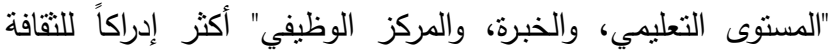

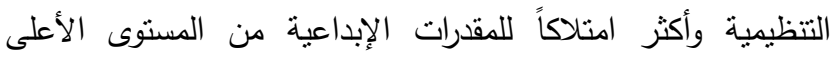

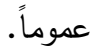

أجرى(ז') دراسة هدفت إلى التعرف على الثقافة التتظيمية وعلاقتها بالإبداع الإداري في مدارس المرحلة الثانوية في دولة الكويت من وجهة نظر المعلمين، وقد تكونت عينة الدراسة من (•ـأب) معلماً

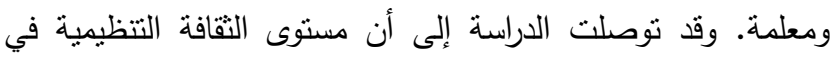
مدارس المرحلة الثانوية في الكويت من وجهة نظر المعلمين كان مرتفعاً، وأن مستوى الإبداع الإداري في مدارس المرحلة الثانوية من

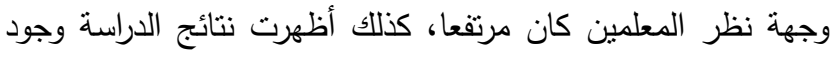

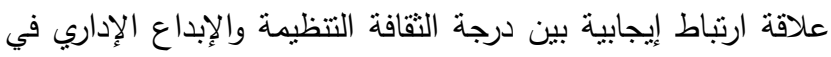
مدارس المرحلة الثانوية في الكويت، كذلك توجد فروق دالة إحصائياً عند مستوى الدلالة ( . .,•>م) لمستوى الثقافة التنظيمية والإبداع الإداري تبعا لمتغير الجنس وكان الفرق لصالح الإناث، وكذلك توجد التدان

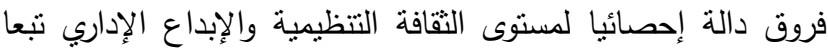
لمتغير المؤهل العلمي وكان الفرق لصالح حملة الماجستير . تتثابه هذه الدراسة مع غالبية الدراسات السابقة في طبيعة موضوعها ، وكذلك استخدام الدنهج الوصفي مثل دراسة(·r)، (1)، (م). كما تتفق الدراسة الحالية دع الدراسات السابقة في أن عينة

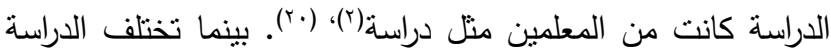
الحالية في تتاولها الثمولي لهجالات النقافة التنظيمة والإبداع الإداري معاً، وأيضا تختلفت هذه الدراسة عن الدراسات السابقة في نتاول الإبداع الإداري في الددارس الخاصة في الأردن، وهذه الفئة فلّما يتناولها الباحثتن التزبويون في البحث، 
وأساليب أكثر كفاءة وفاعلية في إنجاز أهداف المؤسسة التعليمية، وذللك من خلال إجابة أفراد عينة الدراسة على أداة الدراسة.

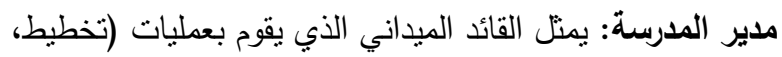

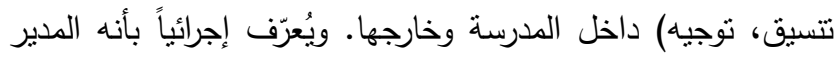
الذي يقوم على إدارة المدرسة الخاصة، ويتولى إدارة شؤونها وفقاً للصلاحيات الممنوحه له ولإجراءات إدارة التعليم الخاص.

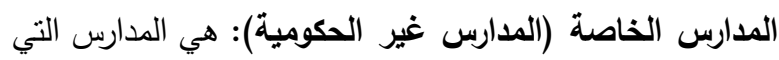

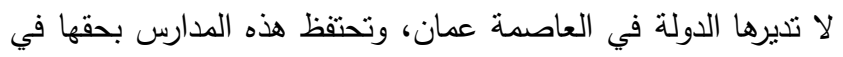
تحديد الطلبة الذين يلتحقون بها، وينم تمويلها كليا أو جزئيا عن طريق فرض رسوم التعليم على الطلبة.

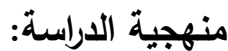

تم استخدام منهجية البحث المسحي الوصفي حيث نم إجراء المسح المكتبي والاطلاع على الدراسات والبحوث النظرية والميدانية ذات الصلة بموضوع الدراسة؛ لأجل بلورة الأسس والمنطلقات التي يقوم عليها موضوع الدراسة، والوقوف على أهم الدراسات التي شكلت التهان

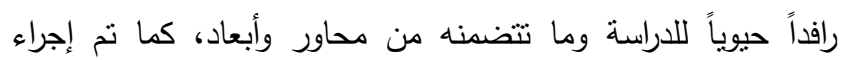

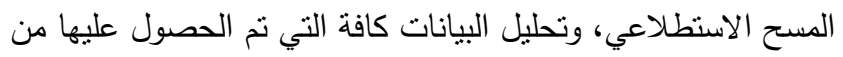
خلال أداتي الدراسة، واستخدام الطرق الإحصائية المناسبة لذلك.

\section{مجتمع الدراسة:}

تكوّن مجتمع الدراسة من كافة معلمي الددارس الخاصة في لدارة

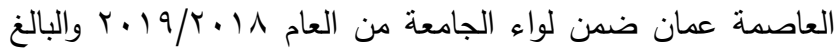
عددهم (8040) معلماً ومعلمة حسب إحصائيات وزارة النربية والتعليم

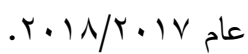

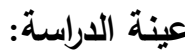

نم اختبار عينة عشوائية عنقودية حيث نم حصر أسماء المدارس الخاصة في عمان والبالغ عددها (Iالr/) مدرسة خاصة،

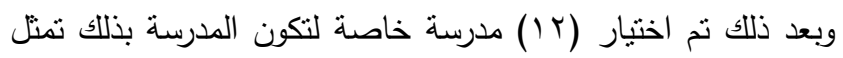
وحدة الاختيار ثم نم تطبيق أداة الدراسة على كافة معلمي المدارس

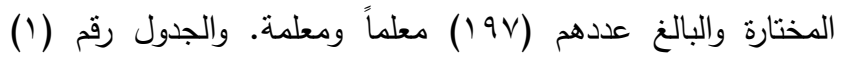
يوضح نوزيع أفراد عينة الدراسة وفقا لمتغيراتها. جدول (1): توزيع أفراد عينة الدراسة وفقاً لمتفيراتها.

\begin{tabular}{|c|c|c|c|}
\hline النسبة المئوية & العدد & فئات المتغير & المتغير \\
\hline$\% \leqslant \wedge$ & 90 & ذكور & \multirow{3}{*}{ الجنس الجس } \\
\hline$\% \circ r$ & $1 . r$ & إناث & \\
\hline$\% 1 \ldots$ & $19 V$ & الكلي & \\
\hline$\%$ rr & $\leq 7$ & أقل من ه سنوات & \multirow{4}{*}{ ل لخبرة الإدارية } \\
\hline$\%$ \%r & or & من •-واقل من • ا سنوات & \\
\hline$\% 01$ & 99 & • ل ا سنوات فأكثر & \\
\hline$\% 1 \ldots$ & $19 V$ & الكلي & \\
\hline
\end{tabular}

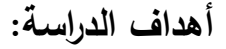

تهدف الدراسة الحالية إلى تحقيق الآتي: الكثف عن نمط النقافة النتظيمية السائدة في المدارس التئ

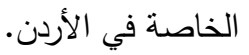
الكثف عن مستوى الإبداع الإداري لدى مديري المدارس الإدن

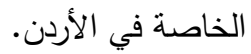

الكثف عن العلاقة بين الثقافة التنظيمية والإبداع الإداري في المدارس الخاصة في الأردن. الكثف عن الفروقات في مستوى الثقافة النتظيمية لاى الادرن الددراء في الددارس الخاصة في الأردن وفقاً لمتغير

$$
\text { (الجنس، الخبرة). }
$$

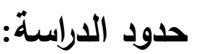

تتمنل حدود هذه الدراسة في الآتي:

تم تتفيذ هذه الدراسة في مدارس التعليم الخاص في في التئ العاصمة عمان في المملكة الأردنية الهاشمية من العام العامين

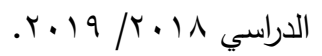

اقتصرت الدراسة الحالية على وجهات نظر عينة من المعلمين والمعلمات في مدارس التعليم الخاص في

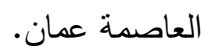

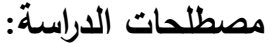

الثقافة التنظيمية: "هي نمط المعتقدات والمزاعم والأفكار والإيديولوجيات والفلسفات التي قامت منظمة ما باختراعها وتنبيها والإجماع بشأنها سواء كان إجماعاً رسمياً من خلا لإل القوانين

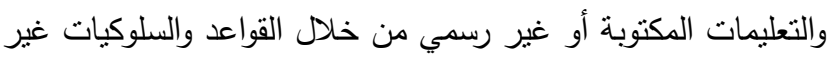
المكتوبة"، وهو ما يُعرف بالعرف السائد في بيئة عمل ما، وبذلك الكئر تكون الثقافة التظيمية يمكن تنبيها ونقلها وتوارثها من جيل إلى جيل جديد (「^). (برن. وتعرف إجرائيا بأنها مجموعة القيم والعادات والممارسات السائدة لدى مدارس التعليم الخاص في الأردن، والتي تحكم سلوكها، وتؤثز على أدائها للأعمال المنوطة بها.

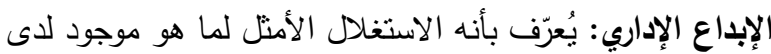

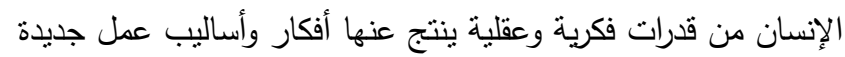
وخلاقة، تتسم بالطلاقة والمرونة والأصالة والحساسية للمشكلات بحيث يمكن تتمية هذه القدرات بالتدريب بناءٌ على قدرة الفرد والجماعة والمنظمة للاستفادة منها في تحسين وتفعيل أداء المنظمة.

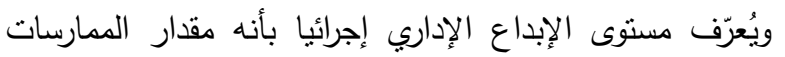

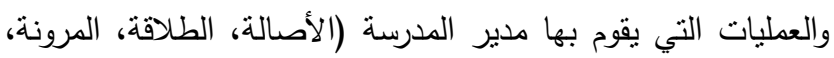
التحليل والربط، الحساسية للمشكلات) والتي تفضي إلى إيجاد طرق 
فقرات من أداة النقافة النتظيمية وتعديل فقرة من مجال إلى مجال آخر، كما تم تعديل فقرتين من حيث الصياغة اللغوية، وفيما ينعلق التقال

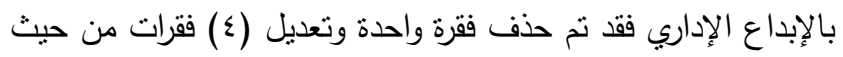
الصياغة بناء على توجيهات المحكمين، ووفقاً لتلك التعديلات فقد تضمنت الاسنبانة في صورتها النهائية (Yo) فقرة للنقافة التظيمية، و (ro) فقرة لمقياس الإبداع الإداري، وأنّ الأخذ بمثل هذه التعديلات

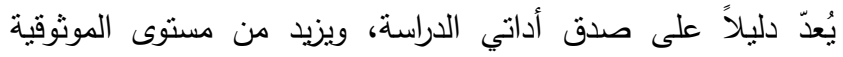
بنتائجها.

\section{صدق الاتساق الاخلي:}

تم التحقق من تجانس أداتي الدراسة داخلياً باستخدام طريقة Construct ( الاتساق الداخلي وهي إحدى طرق صدق التكوين Validity

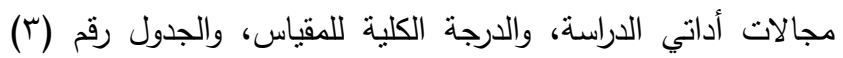
يوضتح نتائج ذلك. جدول (ץ): معاملات ارتباط مجالات أداتي الدراسة مع الدرجة الكلية.

\begin{tabular}{|c|c|c|}
\hline معامل الارتباط & المجال & الأداة \\
\hline$* \cdot, v r$ & قيم العمل & \multirow{5}{*}{ لثقافة التتظيمية } \\
\hline$* \cdot, 79$ & فلسفة العمل & \\
\hline$* \cdot, V V$ & المعتقدات ورسالة المدرسة & \\
\hline$*, \wedge$. & الأعراف والقوانين & \\
\hline$* \cdot, 7$ & النوقعات المستقبلية & \\
\hline$* \cdot, \lambda r$ & الطلاقة & \multirow{5}{*}{ الإبداع الإداري } \\
\hline$*, \uparrow$ & 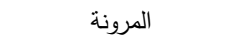 & \\
\hline$* \cdot, v$. & الأصالة & \\
\hline$*, A r$ & الحساسية للمشكلة & \\
\hline$* \cdot, 79$ & المقدرة على المجازفة & \\
\hline
\end{tabular}

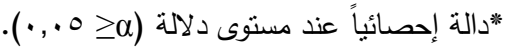

يُظهر الجدول السابق أن جميع معاملات الارتباط بين كل مجال من مجالات أداتي الدراسة، والدرجة الكلية للأداة دالة إحصائيا

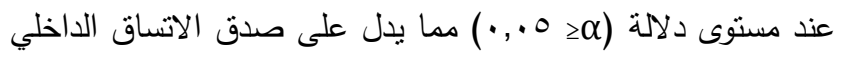

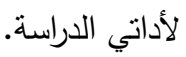

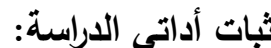

للتحقق من الثبات نم تطبيق أداتي الدراسة والمتمثلة بـ (الثقافة

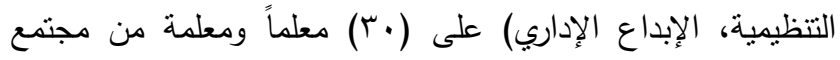

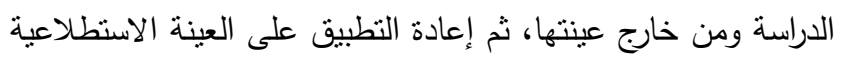

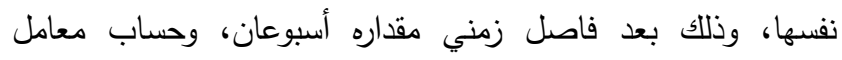

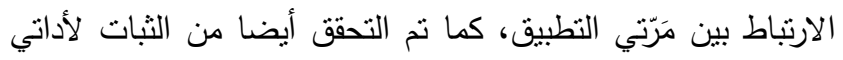
الدراسة عن طريق معامل كرونباخ ألفا (Cronbach's Alpha) للاتساق الداخلي وذللك على مستوى كل مجال من مجالات أداتي

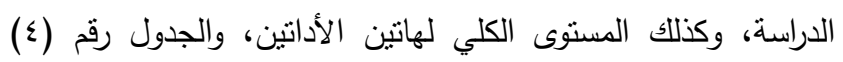
يوضح نتائج ذلك.

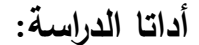

تم نطوير استبانتين لخدمة أغراض الدراسة، الأولى لقياس

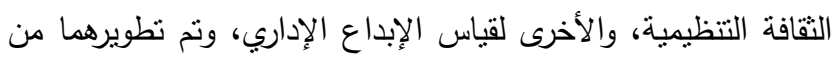
خلال الرجوع إلى الأدب النظري والدراسات السابقة.

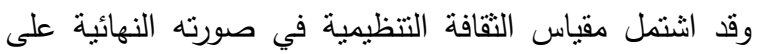
(Y0) فقرة توزعت على (0) مجالات هي (قيم العمل، فلسفة العمل،

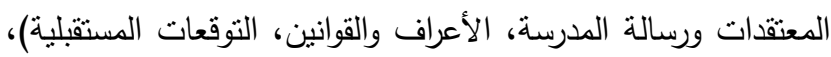

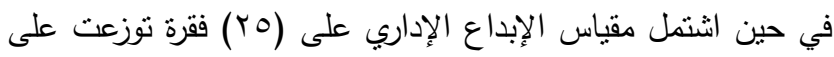
(0) مجالات هي (الطلاقة، المرونة، الأصالة، الحساسية للمشكلات، الإدئ

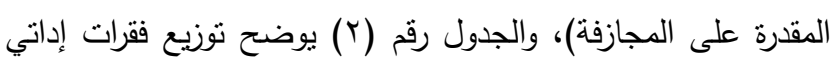
الدراسة على مجالاتها.

جدول رقم (ץ): توزيع فقرات أداتي الدراسة (الثقافة التظظيمة، الإبداع الإداري) على مجالاتها.

\begin{tabular}{|c|c|c|}
\hline عدد الفقرات & 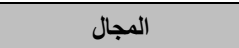 & الأداة \\
\hline 。 & قيم العمل & \multirow{6}{*}{ الثقافة التنظيمية } \\
\hline 。 & فلسفة العمل & \\
\hline 0 & المعتقدات ورسالة المدرسة & \\
\hline 。 & الأعراف والقوانين & \\
\hline 。 & التوقعات المستقبلية & \\
\hline ro & الكلي & \\
\hline 。 & الطلاقة & \multirow{6}{*}{ الابداع الإداري } \\
\hline 。 & المرونة & \\
\hline$\circ$ & الأصالة & \\
\hline 。 & الحساسية للمشكلة & \\
\hline 0 & المقدرة على المجازفة & \\
\hline ro & الكلي & \\
\hline
\end{tabular}

وقد صُمدت أداتا الدراسة وفقا لتدريج ليكرت الخماسي الدكون

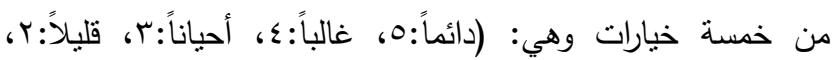
نادراً: ( ).

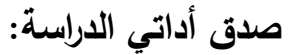

استخدم المؤشرات الآتية للكثف عن صدق أداتي الدراسة،

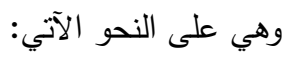
صدق المُحكّمين: للتحقق من صدق أداتي الدراسة ومدى ملاعمتها لتحقيق أهداف

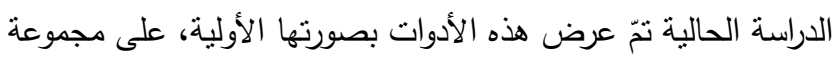

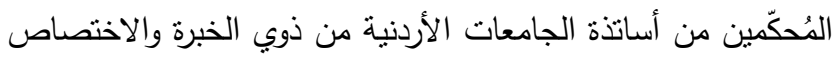

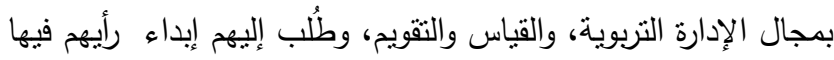
من حيث مدى انتماء كل فقرة للمجال الذي تندرج تحته، ومن حيث الإداء

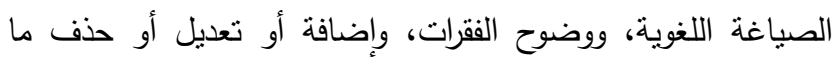

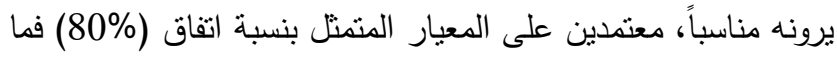
فوق لإبقاء الفقرة وأقل من ذللك لحذفها أو تعديلها، وقد تم الأخذ بمقترحات المحكمين وإجراء التعديلات المطلوبة، حيث تم حذف (r) 
التقافة التنظيمية وعلاقتها بالإبداع الإداري في المدارس الخاصة في الأردن من وجهة نظر المعلمين.

r. انتقاء عينة الدارسة بالطريقة العثوائية البسيطة من مجتمع الدراسة.

ء. لتطبيث أداتي الدراسة، تم توزيع الاستبانات على أفراد عينة

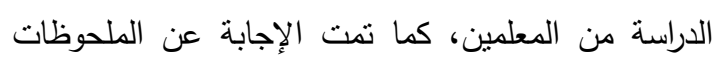

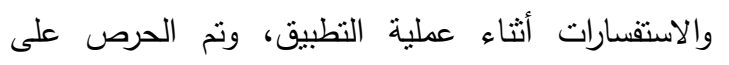
تعريفهم بأهمية الدراسة والإجابة بكل موضوعية عن أداتي الدراسة. ه. تم جمع البيانات وتفريغها في جداول خاصة باستخدام برنامج الرزمة الإحصائية للعلوم الاجتماعية (SPSS) لإجراء التحليلات الإحصائية المناسبة. لفهم المدلولات الإحصائية لمستوى الثقافة التتظيمية، وكذلك الإبداع الإداري، فقد تم الاعتماد في توصيف المستويات

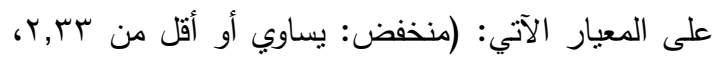

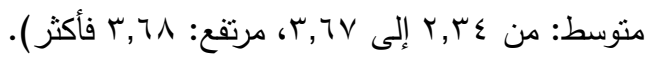

\section{المعالجة الإحصائية: - المانة}

للإجابة عن أسئلة الدراسة تم إجراء المعالجات الإحصائية

$$
\text { باستخدام (SPSS)، وعلى النحو الآتي: }
$$

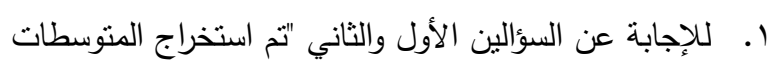

$$
\text { الحسابية والانحرافات المعيارية. }
$$

r. للإجابة عن السؤال الثالث تم استخراج معامل ارتباط بيرسون.

r. للإجابة عن السؤال الرابع تم إجراء تحليل التباين الثنائي

.(Tow way Anova)

ع. للتحقق من ثبات أداتي الدراسة تم استخدام معامل كرونباخ ألفا ومعامل ارتباط بيرسون بين مرّتي التطبيق. ๑. لوصف خصائص عينة الدراسة سيتم استخراج التكرارات

$$
\text { والنسب المئوية. }
$$

\section{عرض النتائج ومناقشتها والتوصيات:}

يتضمن هذا الجزء عرضاً لنتائج الدراسة بعد معالجتها إحصائياً وفقاً لأسئلتها ومناقشة هذه النتائج.

\section{نتائج السؤال الأول، والذي نصه:}

"ما مستوى التقافة التتظيمية السائدة لدى مدراء المدارس الخاصة

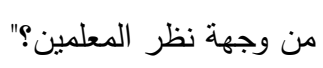

للإجابة عن هذا السؤال تمّ احتساب المتوسّطات الحسابية

والانحرافات المعياريّة لنمط الثقافة التنظيمية السائدة لدى مدراء المدارس الخاصة، وذلك على مستوى كل مجال من مجالات الدراسة

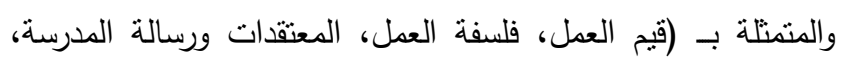

\begin{tabular}{|c|c|c|c|}
\hline معامل كرونباخ ألفا & معامل ارتباط بيرسون & المجال & الأداة \\
\hline$\cdot, \wedge \varepsilon$ & $\cdot, \wedge \mathrm{T}$ & قيم العمل & \multirow{6}{*}{ التنظيمية } \\
\hline$\cdot, \wedge \mathrm{V}$ & $\cdot, \wedge \Lambda$ & فلسفة العمل & \\
\hline$\cdot, \wedge 1$ & 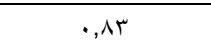 & المعتقدات ورسالة المدرسة & \\
\hline$\cdot, \wedge \wedge$ & $\cdot, 91$ & الأعراف والقوانين & \\
\hline$\cdot, \wedge$ & $\cdot, \wedge r$ & التوقعات المستقبلية & \\
\hline$\cdot, 9$ & $\cdot, 94$ & الكلي & \\
\hline$\cdot, \wedge \varepsilon$ & $\cdot, \wedge 4$ & الطلاقة & \multirow{6}{*}{ الإلبدارع } \\
\hline$\cdot, 9$ & $\cdot, 91$ & 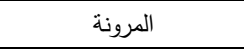 & \\
\hline$\cdot, \wedge \mathrm{T}$ & $\cdot, \wedge \wedge$ & الأصالة & \\
\hline$\cdot, 94$ & $\cdot, \wedge \uparrow$ & الحساسية للمشكلة & \\
\hline$\cdot, \wedge \mathrm{AT}$ & $\cdot, \wedge \wedge$ & المقدرة على المجازفة & \\
\hline$\cdot, \wedge 9$ & $\cdot, 9$ & الكلي & \\
\hline
\end{tabular}
الأعراف والقوانين، التوقعات المستقبلية) والمجال الكلي، والجدول رقم

$$
\text { (0) يوضح نتائج ذلك. }
$$

جدول رقم (ع): معاملات ثبات أداتي الدراسة.

تُظهِر النتائج في الجدول (ع) أن معاملات ثبات أداة الثقافة التتظيمية بطريقة تطبيق وإعادة التطبيق للاختبار قد تراوحت

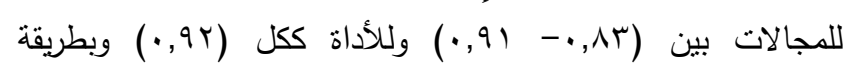

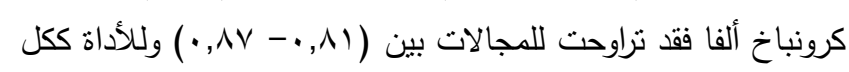

كما تبين النتائج أيضا أن معاملات ثبات أداة الإبداع الإداري بطريقة تطبيق وإعادة التطبيق للاختبار قد نراوحت للمجالات بين

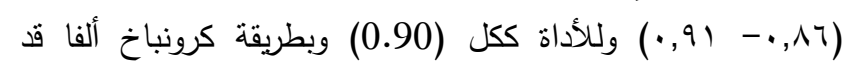

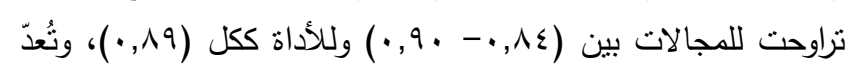
مثل هذه القيم مقبولة لأغراض الدراسة الحالية.

\section{متغيرات الدراسة:}

اشتملت الدراسة الحالية على نوعين من المتغيرات هما: ا . المتغيرات المستقلة الوسيطة (Independent Variable):

$$
\text { وتمنلت في الدراسة الحالية بـ (الجنس، سنوات الخبرة). }
$$

r. المتغيرات التابعة (dependent Variable) وتتمثل بـ: • الثقافة التتظيمية وتُقاس من خلال استجابة أفراد عينة الدراسة على مقياس الثقافة التنظيمية الذي تم إعداده لذلك

$$
\text { الغرض. }
$$

• الإبداع الإداري، ويقاس من خلا استجابة أفراد عينة الدراسة على مقياس الإبداع الإداري الذي تم إعداده لذلك الإند

$$
\text { الغرض. }
$$

\section{إجراءات تطبيق الدراسة:}

لتحقيق هدف الدراسة فقد نم اتباع الإجراءات التالية: ا. تم مراجعة الأدب النظري والدراسات السابقة من أجل بلورة

$$
\text { الأسس النظرية للموضوع. }
$$

r. تحديد متغيرات الدراسة وتطوير أداتي الدراسة والتأكد من

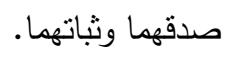


المجلة الدولية لضمان الجودة - المجلد الثاني - العدد الثاني، 9 ـــ.

(الطلاقة، المرونة، الأصالة، الحساسية للمشكلات، المقدرة على المجازفة)، والجدول رقم (؟) يوضح نتائج ذلك. جدول (†): المتوستطات الحسابية والانحرافات المعياريَة لمستوى الإبداع الإداري لاى مديري

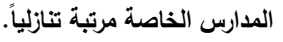

\begin{tabular}{|c|c|c|c|c|}
\hline الدرجة & الانحراف المعياري & المتوسط الحسابي & المجال & الترتيب \\
\hline متوسط & 0.63 & 3.36 & الحساسية للمشكلات & 1 \\
\hline منوسط & 0.99 & 3.20 & الأصالة & r \\
\hline منوسط & 0.87 & 3.13 & الطلاقة & r \\
\hline منوسط & 0.91 & 3.07 & المرونة & $\varepsilon$ \\
\hline منوسط & 0.88 & 2.98 & المقدرة على المجازفة & 0 \\
\hline منوسط & 0.64 & 3.15 & الكلي & - \\
\hline
\end{tabular}

يبين الجدول (؟) أنّ مستوى الإبداع الإداري لدى مديري

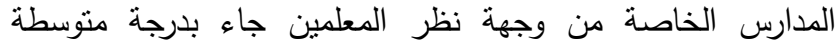

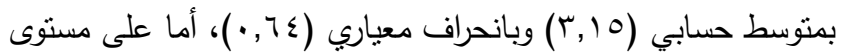
المجالات (الطلاقة، المرونة، الأصالة، الحساسية للشككلات، المقدرة على المجازفة)، فقد جاءت جمبعها بمستوى متوسط، محتلاً المرتبة

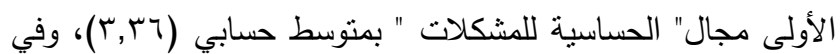
المرتبة الثانية "الأصالة" بمتوسط حسابي بلغ (3.20)، واحتل مجال "الطلاقة" المرتبة الثالثة وبمتوسط حسابي (r, (r,)، وجاء بالمرتبة

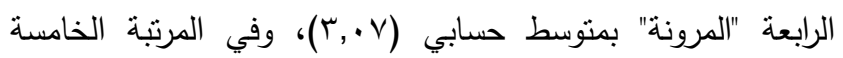
والأخيرة جاء مجال "المقدرة على المجازفة" بمتوسط حسابي (Y,9^).

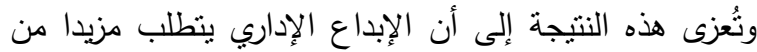

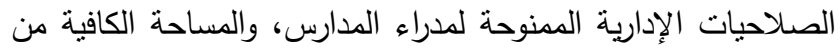

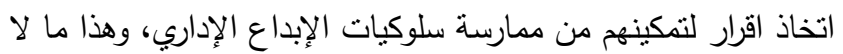

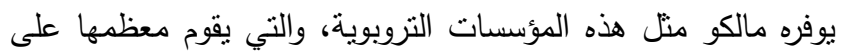

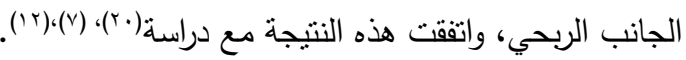

\section{نتائج السؤال الثالث والذي نصه:}

" هل هنالك علاقة ارتباطية ذات دلالة إحصائية عند مستوى نصلئ

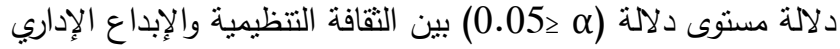

لادى مديري المدارس الخاصة؟

للإجابة عن هذا السؤال تم حساب معامل ارتباط بيرسون بين

الثقافة التنظيمية ممثلة بأبعادها: ( قيم العمل، فلسفة العمل، المعتقدات ورسالة الددرسة، الأعراف والقوانين، التوقعات المستقبلية) مع الإبداع الإداري ممثلاً بأبعاده (الطلاقة، المرونة، الأصالة، الحساسية الإناء

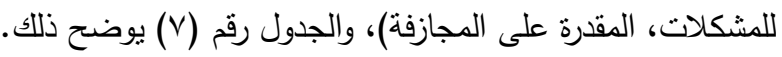

جذول (v): مصفوفة معامل ارتباط بيرسون للعلاقة بين الثقافة التظيمية والإبداع الإداري.

\begin{tabular}{|c|c|c|c|c|c|c|}
\hline \multicolumn{6}{|c|}{ الابعاد التابعة " الابداع الاداري " } & \multirow{2}{*}{ الابعادة التستيمية } \\
\hline الكلي & القدرة على & للمشكلات & أصالة & مرونة & طلاقة & \\
\hline $0.40 *$ & $0.55^{*}$ & $0.70 *$ & $0.33 *$ & $0.27 *$ & $0.32 *$ & قيم العمل \\
\hline $0.53 *$ & $0.55^{*}$ & $0.60 *$ & $0.40 *$ & $0.51 *$ & $0.45^{*}$ & فلسفة العمل \\
\hline $0.49 *$ & $0.49 *$ & $0.47 *$ & $0.28 *$ & $0.31 *$ & $0.37 *$ & المتندات ورسالة \\
\hline
\end{tabular}

جدول (0): المتوسيّات الحسابية والانحرافات المعياريّة لاستجابات أفراد عينة

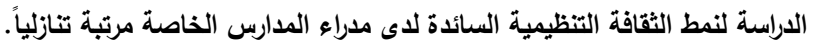

\begin{tabular}{|c|c|c|c|c|}
\hline الدرجة & الانحراف المعياري & المتوسط الحسابي & المجال & الترتيب \\
\hline مرتفع & 0.72 & 3.90 & المعتقدات ورسالة المدرسة & 1 \\
\hline مرتفع & 0.59 & 3.83 & الأعراف والقوانين & $r$ \\
\hline مرتفع & 0.46 & 3.74 & قيم العمل & $r$ \\
\hline مرتفع & 0.51 & 3.72 & فلسفة العمل & $\varepsilon$ \\
\hline مرتفع & 0.83 & 3.69 & التوقعات المستقبلية & o \\
\hline مرتفع & 0.45 & 3.77 & الكلي & - \\
\hline
\end{tabular}

يبين الجدول (0) أنّ المتوسطات الحسابية لنمط النقافة التنظيمية السائدة لدى مدراء الددارس الخاصة وعلى المستوى الكلي جاء بدرجة مرتفعة بمتوسط حسابي (r,VV) وبانحراف معياري (إ), )، أما على مستوى المجالات (قيم العمل، فلسفة العمل، المعتقدات ورسالة المدرسة، الأعراف والقوانين، النوقعات المستقبلية)، فقد جاءت جميعها بمستوى مرتفع، محتلاً المرتبة الأولى مجال" المعتقدات ورسالة المدرسة" بمتوسط حسابي (3.90)، وفي المرتبة الثانية " الأعراف والقوانين" بمتوسط حسابي بلغ (3.83)، واحتل بلت مجال " قيم العمل" المرتبة الثالثة وبمتوسط حسابي (3.74)، وجاء الثاء بالمرتبة الرابعة "فلسفة العمل" بمتوسط حسابي(3.72)، وفي المرتبة

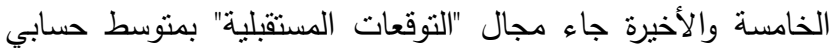

وتُعزى هذه النتيجة إلى أن لكل مدرسة ثقافةً تتظيميةً خاصةً

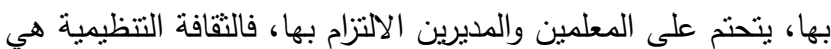
ما يميز الدارس بعضها عن بعض، كما تعكس هذه النتيجة محاولة

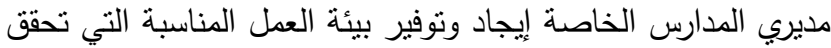
الرضا للعاملين، وغرس القيم المشجعة على دعم الثقافة التنظيمية، وهذا ينعكس على العمل الجماعي المثمر الذي يحقق ثقافة تتظيمية بمستوى مرتفع. وأيضا يمكن عزو ارتفاع تقدير الدرجة الكلية لطبيعة العمل في الددارس الخاصة، وشروطها التي تُمليها على الموظفين، والتي ترنبط ببقائهم بهذه الددارس مقارنة بالمدارس الحكومية.وهذا

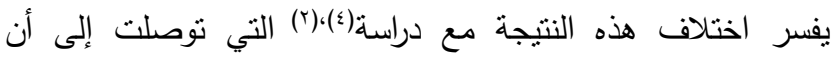

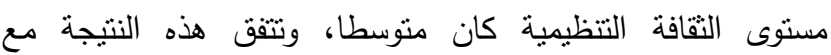
دراسة(r)(r(v) التي توصلت إلى أن مستوى النقافة التتظيمية كان

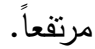

\section{نتائج السؤال الثاني، والذي نصه:}

" ما مستوى الإبداع الإداري لاى مديري الدارس الخاصة من الصناس

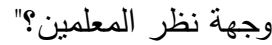

للإجابة عن هذا السؤال تمّ احتساب المتوسّطات الحسابية والانحرافات المعياريّة لاستجابات أفراد عينة الدراسة على مقياس

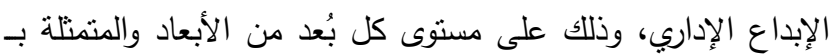


الثقافة التنظيمية وعلاقتها بالإبداع الإداري في المدارس الخاصة في الأردن من وجهة نظر المعلمين.

جدول رقم (^): المتوسطات الحسابية والانحرافات المعيارية لتقيرات المعلمين لمستوى الثقافة التظظيمية لاى مديري المدارس الخاصة تُغزى للمتغيرات (الجنس، الخبرة).

\begin{tabular}{|c|c|c|c|c|}
\hline الانحراف & المسابي & الفئات & 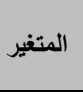 & المجال \\
\hline 0.36 & 3.70 & ذكر & \multirow{2}{*}{ 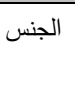 } & \multirow{5}{*}{ قيم العمل } \\
\hline 0.65 & 3.81 & أثثى & & \\
\hline 0.64 & 3.72 & أقل من خمس سنوات & \multirow{3}{*}{ الخبرة الخ } & \\
\hline 0.41 & 3.81 & من 5 - اقل من 10 سنوات & & \\
\hline 0.64 & 3.69 & 10سنوات فأكثر & & \\
\hline 0.49 & 3.69 & ذكر & \multirow[t]{2}{*}{ 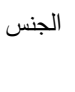 } & \multirow{5}{*}{ فلسفة العمل } \\
\hline 0.80 & 3.74 & أثثى & & \\
\hline 0.90 & 3.62 & أقل من خمس سنوات & \multirow{3}{*}{ الخبرة الخبرة } & \\
\hline 0.91 & 3.71 & من 5 - أقل من 10 سنوات & & \\
\hline 0.54 & 3.77 & 10سنوات فأكثر & & \\
\hline 0.42 & 4.01 & ذكر & \multirow[t]{2}{*}{ 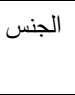 } & \multirow{5}{*}{ ورسالة المدرسة } \\
\hline 0.45 & 3.87 & أثثى & & \\
\hline 0.66 & 3.92 & أقل من خمس سنوات & \multirow{3}{*}{ الخبرة الخبر } & \\
\hline 0.46 & 3.86 & من 5 - اقل من 10 سنوات & & \\
\hline 0.41 & 3.87 & 10سنوات فأكثر & & \\
\hline 0.48 & 3.85 & ذكر & \multirow[t]{2}{*}{ 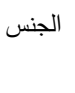 } & \multirow{5}{*}{ الأعراف } \\
\hline 0.49 & 3.80 & أثثى & & \\
\hline 0.66 & 3.88 & أقل من خمس سنوات & \multirow{3}{*}{ الخبرة الخبرة } & \\
\hline 0.46 & 3.74 & من 5 - اقل من 10 سنوات & & \\
\hline 0.51 & 3.78 & 10سنوات فأكثر & & \\
\hline 0.40 & 3.72 & ذكر & \multirow[t]{2}{*}{ 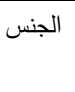 } & \multirow{5}{*}{ التوقتعات } \\
\hline 0.97 & 3.66 & أثثى & & \\
\hline 0.60 & 3.64 & أقل من خمس سنوات & \multirow{3}{*}{ الخبرة الخ } & \\
\hline 0.47 & 3.72 & من 5 - اقل من 10 سنوات & & \\
\hline 0.98 & 3.70 & 10سنوات فأكثر & & \\
\hline 0.30 & 3.80 & ذكر & \multirow[t]{2}{*}{ الجنس } & \multirow{5}{*}{ الكلي } \\
\hline 0.48 & 3.75 & أثنى & & \\
\hline 0.59 & 3.72 & أقل من خمس سنوات & \multirow{3}{*}{ الخبرة الخبرة } & \\
\hline 0.40 & 3.75 & من 5 - أقل من 10 سنوات & & \\
\hline 0.44 & 3.70 & 10سنوات فأكثر & & \\
\hline
\end{tabular}

تشير البيانات الواردة في الجدول (^) إلى وجود فروقات ظاهرية في المتوسطات الحسابية لتقديرات المعلمين لمستوى الثقافة

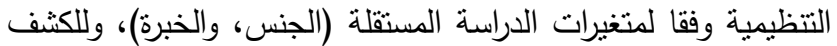
فيما إذا كانت هذه الفروقات ذات دلالة إحصائية نم استخدام تحليل

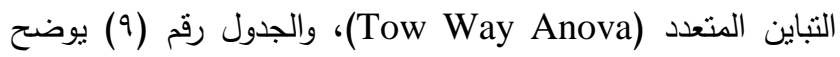
نتنائج ذلك. جدول (9): نتائج تحليل التباين الثنائي للكثف عن الفروق في تقديرات المعلمين لمستوى الثقافة التظظيمية لاى مديري المدارس الخاصة تُونى للمتغيرات (الجنس، الخبرة).

\begin{tabular}{|c|c|c|c|c|c|c|}
\hline مستوى الدلالة & قيمة & المريعات & لدرجات & المربعات & مصدر التباين & المجال \\
\hline 0.796 & 0.067 & 0.026 & 1 & 0.026 & الجنس & \multirow{5}{*}{ ثيم العمل } \\
\hline \multirow[t]{4}{*}{0.188} & 1.687 & 0.648 & 2 & 1.297 & الخبرة & \\
\hline & & 0.384 & 193 & 74.167 & الخطأ & \\
\hline & & & 197 & 3475.360 & الكلي & \\
\hline & & & 196 & 75.469 & الكلي المصحح & \\
\hline
\end{tabular}

\begin{tabular}{|c|c|c|c|c|c|c|}
\hline \multicolumn{6}{|c|}{ الابعاد التابعة " الابداع الاداري " } & \multirow{2}{*}{ " الابعاد المستقلة } \\
\hline الكلي & القدرة على & للمشكلات & أصالة & 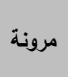 & طلاقة & \\
\hline $0.46^{*}$ & $0.50 *$ & $0.59^{*}$ & $0.27 *$ & $0.26^{*}$ & $0.38 *$ & الأعراف والقوانين \\
\hline $0.51^{*}$ & $0.68^{*}$ & $0.61^{*}$ & $0.31 *$ & $* 0.30$ & $0.55 *$ & التوقعات المستقبلية \\
\hline $0.60 *$ & $0.59 *$ & $0.61 *$ & $0.66^{*}$ & $0.73 *$ & $0.44 *$ & 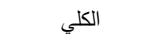 \\
\hline
\end{tabular}

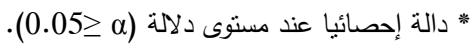

يتضح من الجدول رقم (V)، أن جميع العلاقات الارتباطية دالّة التّات إحصائياً، وعند مستويات إيجايية بين المتغيرات المستقلة لمجالات

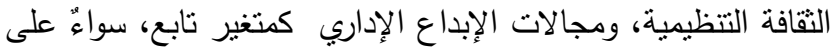

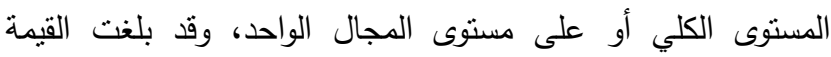

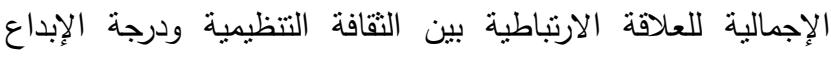
الإداري ككل (·r, ·) وهي قيمة إيجابية تؤكد وجود ارتباط طردي عالٍ بين الثقافة التنظيمية والإبداع الإداري لدى مديري المدارس الداس

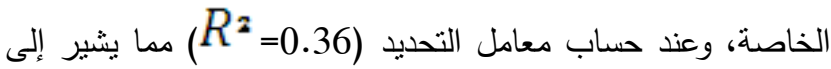
أن معرفتتا بالثقافة التتظيمية لمديري المدارس الخاصة كمتغير مستقل يفسر ما مقداره (דr\%) من التباين في المتغير التابع (الإبداع

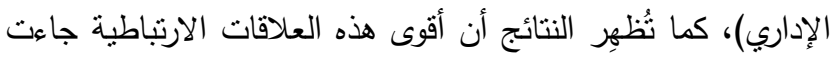

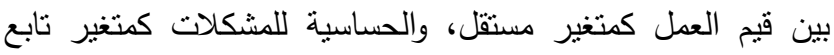
حيث بلغت قوة هذه العلاقة الارتباطية (·•,•)، في حين كانت أضعف هذه العلاقات الارتباطية هي العلاقة بين المتغير الدسنقل

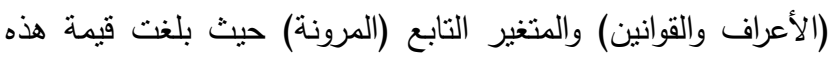

العلاقة الارتباطية († ז, ·).

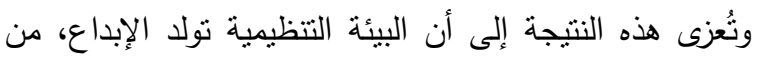

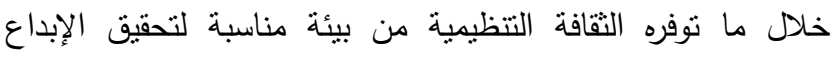
الإداري لدى المعلمين في المدارس الخاصة، إذ تُعدالثقافة النتظيمة

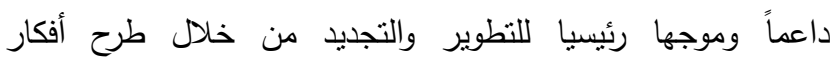
واستراتيجيات مبتكره، ووضع سياسات تحقق التطور والازدهار للمؤسسة التزبوية. وتتفق هذه النتيجة مع دراسة(ז')، ودراسة (0).

\section{نتائج السوأل الرابع والذاي نَصُه:}

"هل توجد فروق ذات دلالة إحصائية عند مسنوى دلالة (هنائ 20.052) في تقديرات المعلمين لمستوى النقافة التنظيمية لاى مديري المدارس الخاصة تُعزى للمتغيرات (الجنس، الخبرة)؟ للإجابة عن هذا السؤال نم حساب المتوسطات الحسابية

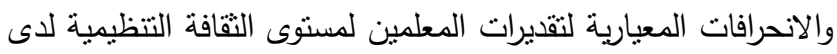
مديري المدارس الخاصة تُعزى للمتغيرات (الجنس، الخبرة)، والجدول (^) يوضح ذلك. 
المجلة الدولية لضمان الجودة - المجلد الثاني - العدد الثاني، 19 ــr.

وتختلف هذه النتيجة مع دراسة(r') ودراسة(V) التي أظهرث وجود فروق ذات دلالة إحصائية لارجة الثقافـة التتظيمية في المدارس الثانوية في الكويت تبعا لمتغير الخبرة، إذ كان الفرق لصالح فئة (09) عند مقارنتها مع فئة ( • ( سنوات فأكثر).

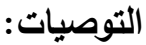

ضروة إعداد مديري المدارس الخاصة وتأهيلهم ومن ثم توظيفهم في مواقعهم، لضمان جاهزيتهم لممارسة العمل الإداري الإبداعي في البيئة المدرسية. الاستفادة من التجارب الدولية في مجال الإدارة والتخطيط التربوي والإبداع الإداري. إجراء المزبد من الدراسات من قبل الباحثين الآخرين لاختبار العلاقة بين متغيرات الدراسة في بيئات أخرى منل ملت المدارس الحكومية أو العسكرية أو الأنروا. توجية صناع القرار وراسمي السياسات التربوية إلى ضرورة الاهنمام بضوابط انتقاء واختبار مدراء المدارس العاملين في القطاع الخاص وبما يضمن جاهزيتهم للعمل الإداري

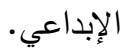

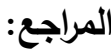

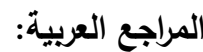

ا. أبو بكر، محمود. خصائص الأنماط القيادية في الواقع

العدلي ومتطلبات التفكير الاستراتيجي في المنظمات

المعاصرة. القاهرة: ايتراك للنشر والتوزيع، ب . . r. r. أبو جامع، ابراهيم. الثقافة التظظيمية والإبداع الإداري في وزارة التربية والتعليم الأردنية، أطروحة دكتوراه غبر منشورة،

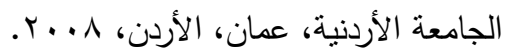
r. أبو الوفا، جمال. دور قيادات المدرسة الابتدائية في نتمية الإبداع الجماعي لاى العاملين بها لمواجهة تحديات العولمة" دراسة ميدانية"، مجلة مستقبل التربية العربية، باعية . Y. T ، 10V - Or ، EY. ع. المومني، خالد. مستوى الثقافة التنظيمية في المدارس الثانوية في محافظة عجلون في الأردن من وجهة نظر المعلمين. مجلة الزرقاء للبحوث والدراسات الإنسانية، ل IV $. \Sigma T V_{6} T+1 V-1, \varepsilon r T$ 0. العنزي، بسام. الثقافة التظيمية والإبداع الإداري، رسالة ماجستبر غير منشورة، جامعة الملك سعود، الرياض، المملكة العربية السعودية، ع . . ب. 7. العنزي، عويد. مستوى الإبداع الإداري لدى مديري المدارس في شمال المملكة العربية السعودية من وجهة نظر المعلمين

\begin{tabular}{|c|c|c|c|c|c|c|}
\hline مستوى & قَ) & متوسطع & الرية & المربعات & مصدر التباين & المجال \\
\hline .694 &. .155 & .069 & 1 & .069 & الجنس & \multirow{5}{*}{ فلعلة } \\
\hline \multirow[t]{4}{*}{. .192} & 1.665 &. .742 & 2 & 1.484 & الخبرة & \\
\hline & &. .446 & 193 & 86.014 & الخطأ & \\
\hline & & & 197 & 2999.480 & الكلي & \\
\hline & & & 196 & 87.527 & الكلي المصحح & \\
\hline. .606 & .266 & .198 & 1 & .198 & الجنس & \multirow{5}{*}{ المرسالة } \\
\hline \multirow[t]{4}{*}{.281} & 1.278 & .948 & 2 & 1.895 & الخبرة & \\
\hline & & .741 & 193 & 143.107 & الخطأ & \\
\hline & & & 197 & 2986.760 & الكلي & \\
\hline & & & 196 & 145.119 & الكلي المصحح & \\
\hline. .532 & .393 &. .059 & 1 & .059 & الجنس & \multirow{5}{*}{ والأعراف } \\
\hline \multirow[t]{4}{*}{.199} & 1.627 &. .243 & 2 & .485 & الخبرة & \\
\hline & &. .149 & 193 & 28.792 & الخطأ & \\
\hline & & & 197 & 3422.560 & الكلي & \\
\hline & & & 196 & 29.312 & الكلي المصحح & \\
\hline. .628 & .236 &. .127 & 1 & .127 & الجنس & \multirow{5}{*}{ التونقعات } \\
\hline \multirow[t]{4}{*}{. .220} & 1.526 &. .821 & 2 & 1.643 & الخبرة & \\
\hline & &. .538 & 193 & 103.895 & الخطأ & \\
\hline & & & 197 & 3053.040 & الكلي & \\
\hline & & & 196 & 105.609 & الكلي المصحح & \\
\hline. .605 & .269 & 0.086 & 1 & .086 & الجنس & \multirow{5}{*}{ الكلي } \\
\hline \multirow[t]{4}{*}{.157} & 1.872 &. .598 & 2 & 1.197 & الخبرة & \\
\hline & &. .320 & 193 & 61.710 & الخطأ & \\
\hline & & & 197 & 3156.979 & الكلي & \\
\hline & & & 196 & 62.950 & الكلي المصحح & \\
\hline
\end{tabular}

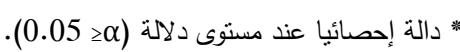

تشير البيانات الواردة في الجدول رقم (9) إلى عدم وجود فروق

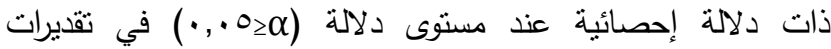
المعلمين لمستوى التقافة التتظيمية لدى مديري المدارس الخاصة تُعزى للمتغيرات (الجنس، الخبرة). وتُعزى نتائج الدراسة بالنسبة لمتغير الجنس إلى أن المدرسة هي مؤسسة تعليمية وتربوية تسعى لتحقيق غايات تعليمية وتربوية، وتعامل جميع المعلمين ذكورا أو إناثا على حد سواء في ضوء الغايات السابقة، وبالتالي لا نتأثز الثقافة التنظيمية بجنس المعلمين في المدارس الخاصة، واتققت نتائج هذ الدراسة مع دراسةة(؛) التي توصلت إلى عدم وجود فروق دالة إحصائياً لاستجابات عينة الِّارسة على مستوى الثقافة التظيمية لاى مديري المدارس الثانوية في محافظة عجلون من وجهة نظر المعلمين بسبب اختلاف فئات الجنس في جميع المجالات. وتختلف هذه النتيجة مع دراسة(r)،(V) التي أظهرت وجود فروق ذات دلالة إحصائية لمستوى التقافة التتظيمية في مدارس المرحلة الثانوية في الكوبت تبعا لمتغير الجنس، ووجدت الفروق في جميع المجالات نُعزى لصالح الإناث. أما بالنسبة لمتغير الخبرة فيشير إلى أن الاتجاه نحو الثقافة التنظيمية لايختلف عليها المعلمون سواء من ذوي الخبرات الطويلة أو القصيرة، وبالتالي يتفقون في المفاهيم والأطر العامة للتطوير التظظيمي، ومن ضمنها مفهوم الثقافة. 
9 1 الهواري، سيد. الإدارة: الأصول والأسس والهبادئ. القاهرة:

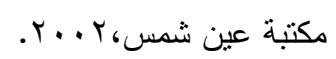

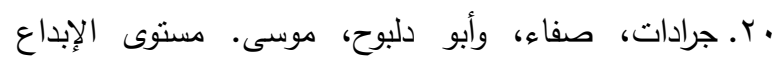

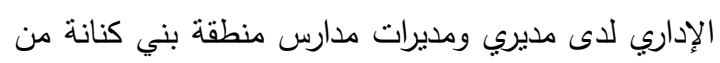

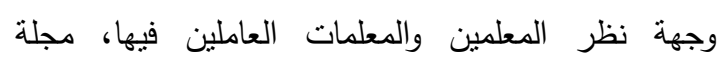

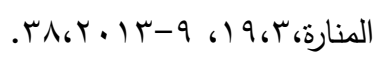

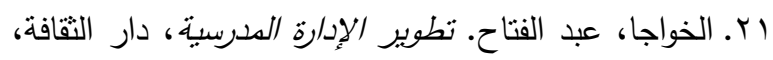

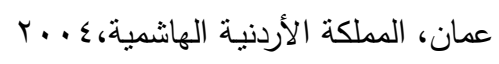

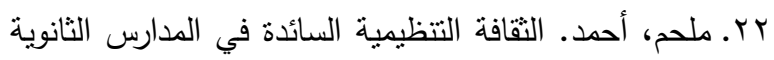

في الأردن، أطروحة دكتوراه غير منشورة. جامعة عمان

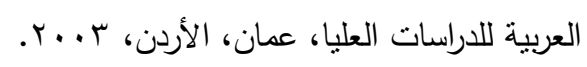

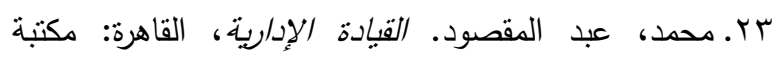

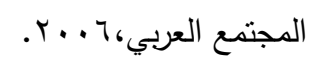

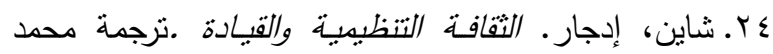

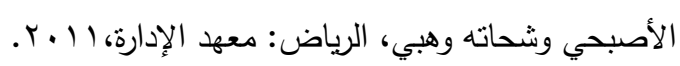

\section{English References:}

25. Galvan, C., Spatzier, C. and Juvonen, G. Perceived norms and socialvalues to capture school culture in elementary and middle schools.Journal of Applied Developmental Psychology, Vol. 32, No.(2) ,P.346353,2011.

26. Guilford, j. p Creative talents: Their nature, uses and development, New York: bearly cimited, 1986

27. Jones,N. The Paradox of Diversity Management, Creativity and Innovation. Creativity and Innovation Management. Vol .14,No .2,p169-175,2005.

28. Kavanagh, M. The Impact of Leadership and Change Management Strategy on Organizational Culture and Individual Acceptance ofChange during a Merger. British Journal of Management, Vol 21.No 3.p 81-103,2006.

29. Rikards,and T,Moger,s. Creative Leaders: A Decade of Contributions from Creativity and Innovation Management . Journal of Creativity and Innovation Management.Vol.15, No.1.p4-18,2006

30. Sanger, T., and Levin, W. Increasing Employees creativity by training their managers. Industrial and commercial training, Vol. 33,No .2,p 63-68,2005.

31. Wfry, R. The Relationship between Principals innovative style And teachers perception of Principals Effectiveness, Dissertation Abstract International. Vol. 456 ,No 7. P. 3100.2006.

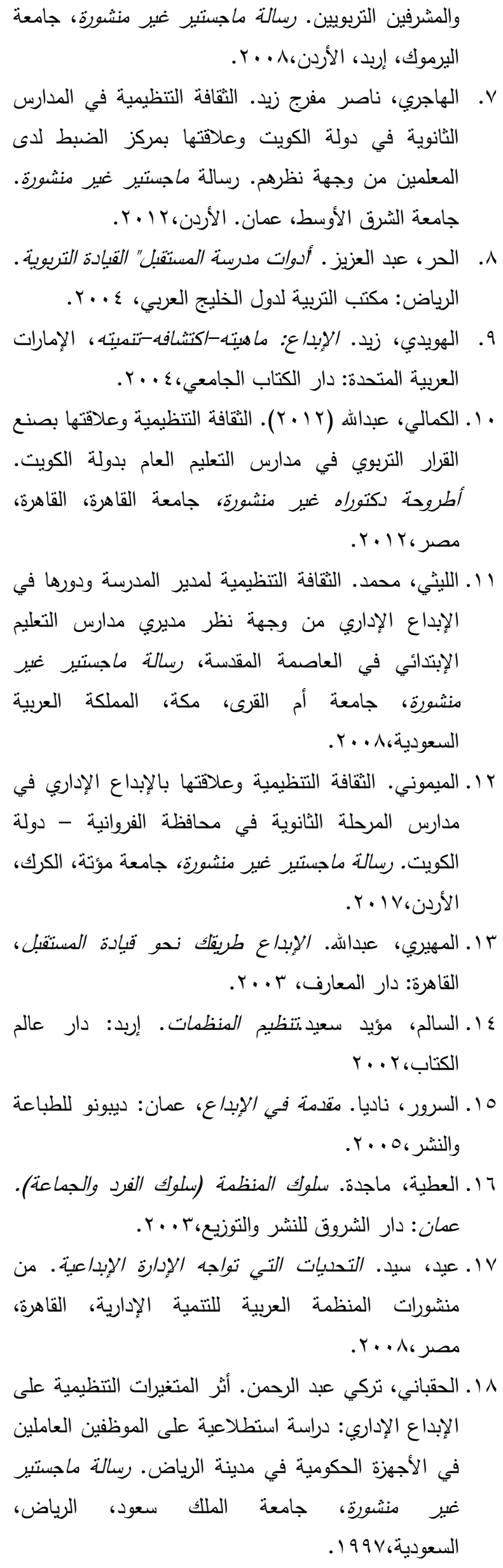


Unpublished Master Thesis, Umm Al-Qura University, Mecca, Saudi Arabia, 2008.

12. Almaimouni, Organizational culture and its relation to administrative creativity in secondary schools in Farwaniya Governorate - State of Kuwait. Unpublished Master Thesis, Mu'tah University, Karak, Jordan, 2017.

13. ALMuhairi, Abdullah. Innovation Your Way to Leading the Future, Cairo: Dar El Maaref, 2003.

14. Al-Salem, Moayad Saeed, Organization of Organizations. Irbid: Dar Alam Al-Kitab, 2002.

15. Alsarur, Nadia. Introduction to Creativity, Oman: Debono for Printing and Publishing, 2005.

16. Attiyah, Magda. Organization Behavior (Individual and Group Behavior). Amman: Al-Shorouk Publishing \& Distribution, 2003.

17. Eid, mister. Challenges to creative management. Publications of the Arab Organization for Administrative Development, Cairo, Egypt, 2008.

18. Haqbani, Turki Abdul Rahman. The Effect of Organizational Variables on Administrative Innovation: Unpublished Master Thesis, King Saud University, Riyadh, Saudi Arabia, 1997.

19. Houari, Sid. Asset management, principles and principles. Cairo: Ain Shams Library, 2002.

20. Jaradat, Safa, and Abu Dalbouh, Musa. The level of administrative creativity of school principals in Bani Kenana area from the perspective of teachers working in it, AlManara Magazine, 19.3, 9-38.2013.

21. Khawaja, Abdul Fattah. Development of School Administration, Dar Al Thaqafa, Amman, Hashemite Kingdom of Jordan, 2004.

22. Melhem, Ahmed. The prevailing organizational culture in secondary schools in Jordan, unpublished doctoral thesis. Amman Arab University for Graduate Studies, Amman, Jordan, 2003

23. Muhammad, Abdul Maqsood. Administrative Leadership, Cairo: Arab Society Library, 2006.

24. Shine, Edgar. Organizational culture and leadership. Translation of Mohammed AlAsbahi and Shehata Wahbi, Riyadh: Institute of Management, 2011.

\section{Translated References:}

1. Abu Bakr, Mahmoud. Characteristics of leadership styles in practice and the requirements of strategic thinking in contemporary organizations: Itrac Publishing and Distribution, 2002.

2. Abu Jama, Ibrahim. Organizational Culture and Administrative Creativity in the Jordanian Ministry of Education, unpublished doctoral thesis, University of Jordan, Amman, Jordan, 2008.

3. Abu Wafa, Jamal. The Role of Leaders of Primary Schools in Developing the Collective Creativity of their Employees to Meet the Challenges of Globalization, "A Field Study", Journal of the Future of Arab Education, 12, 42, 53-157, 2006.

4. Al Momani, Khalid. The level of organizational culture in secondary schools in Ajloun Governorate Zarqa Journal for Research and Humanities, 17, 1,422437,2017.

5. Al-Anazi, Bassam. Organizational Culture and Administrative Creativity, Unpublished Master Thesis, King Saud University, Riyadh, Saudi Arabia, 2004.

6. Al-Anazi, Owaid. The level of administrative creativity of school principals in the north of Saudi Arabia from the point of view of teachers and supervisors. Unpublished Master Thesis, Yarmouk University, Irbid, Jordan, 2008.

7. Al-Hajri, Nasser Mufrej Zaid, Organizational Culture in Secondary Schools in the State of Kuwait and its Relationship with the Control Center of Teachers from their Perspective. A magister message that is not published. Middle East University, Amman. Jordan, 2012.

8. Al-Har, Abdul Aziz . "Future School Tools" Educational Leadership. Riyadh: Gulf Education Bureau, 2004.

9. AL-HUWAIDI, Zaid. Creativity: What it is Discovery - Development, United Arab Emirates: University Book House, 2004.

10. Al-Kamali, Abdullah (2012). Organizational culture and its relationship to educational decision-making in public schools in Kuwait. Unpublished doctoral thesis, Cairo University, Cairo, Egypt, 2012.

11. Al-Laithi, Mohammed. The Organizational Culture of the Principal and its Role in Administrative Creativity from the Point of View of the Principals of Education Schools. The Role in Administrative Creativity from the Point of View of Principals of Primary Education Schools in the Holy Capital, 